NBER WORKING PAPER SERIES

TAMING THE BIAS ZOO

\author{
Hongqi Liu \\ Cameron Peng \\ Wei A. Xiong \\ Wei Xiong
}

Working Paper 26911

http://www.nber.org/papers/w26911

\author{
NATIONAL BUREAU OF ECONOMIC RESEARCH \\ 1050 Massachusetts Avenue \\ Cambridge, MA 02138 \\ March 2020, Revised January 2021
}

\begin{abstract}
We thank Jingxuan Chen and $\mathrm{Zi}$ Ye for able research assistance. For helpful comments, we thank Nick Barberis, Hui Chen, Thummim Cho, James Choi, Bing Han, David Hirshleifer, Rawley Heimer, Sam Hartzmark, Xing Huang, Lawrence Jin, Christian Julliard, Terry Odean, Søren Leth-Petersen, Andrei Shleifer, Johannes Stroebel, Martin Weber, and seminar participants at Baruch, the CEPR Household Finance Workshop, Chapman, CUHK Shenzhen, Imperial College, INSEAD, LSE, the NBER Behavioral Finance Meeting, Princeton, the Red Rock Finance Conference, and Tilburg. Cameron Peng acknowledges financial support from the Paul Woolley Centre at LSE. Wei A. Xiong acknowledges support from the National Natural Science Foundation of China (Project Number 71703104). An earlier version of this paper was circulated under the title "Resolving the Excessive Trading Puzzle: An Integrated Approach Based on Surveys and Transactions." The views expressed herein are those of the authors and do not necessarily reflect the views of the National Bureau of Economic Research.
\end{abstract}

NBER working papers are circulated for discussion and comment purposes. They have not been peer-reviewed or been subject to the review by the NBER Board of Directors that accompanies official NBER publications.

(C) 2020 by Hongqi Liu, Cameron Peng, Wei A. Xiong, and Wei Xiong. All rights reserved. Short sections of text, not to exceed two paragraphs, may be quoted without explicit permission provided that full credit, including $(\odot$ notice, is given to the source. 
Taming the Bias Zoo

Hongqi Liu, Cameron Peng, Wei A. Xiong, and Wei Xiong

NBER Working Paper No. 26911

March 2020, Revised January 2021

JEL No. G02,G41,G53

\begin{tabular}{|c|c|}
\hline \multicolumn{2}{|c|}{ ABSTRACT } \\
\hline $\begin{array}{l}\text { The success of the behavioral economics liter } \\
\text { behavioral biases offering observationally sin } \\
\text { markets. To tame the bias zoo, we propose } \\
\text { responses with observational data; this appro } \\
\text { specific biases introduced through surveys. } \\
\text { nationwide survey of Chinese retail investor } \\
\text { regressions of respondents' actual turnover } \\
\text { perceived information advantage and gamblir } \\
\text { they are not the most prevalent biases simply }\end{array}$ & $\begin{array}{l}\text { o a new challenge-a large nu } \\
\text { ns for a targeted anomaly in } \\
\text { oach of combining subjective } \\
\text { dvantage of being robust to } \mathrm{q} \\
\text { e this approach by adminis } \\
\text { ir trading motives. In cross-s } \\
\text { based measures of trading } \\
\text { dominate other motives, ever } \\
\text { ey responses. }\end{array}$ \\
\hline $\begin{array}{l}\text { Hongqi Liu } \\
\text { Chinese University of Hong Kong, Shenzhen } \\
\text { School of Management and Economics } \\
\text { Longgang, Shenzhen } \\
\text { China } \\
\text { hongqiliu@ cuhk.edu.cn }\end{array}$ & $\begin{array}{l}\text { Wei A. Xiong } \\
\text { Shenzhen Stock Exchange } \\
2012 \text { Shennan Blvd. } \\
\text { Shenzhen } \\
\text { China } \\
\text { wxiong@ szse.cn }\end{array}$ \\
\hline $\begin{array}{l}\text { Cameron Peng } \\
\text { London School of Economics } \\
\text { Houghton Street } \\
\text { London } \\
\text { WC2A 2AE } \\
\text { UK } \\
\text { c.peng9@1se.ac.uk }\end{array}$ & $\begin{array}{l}\text { Wei Xiong } \\
\text { Princeton University } \\
\text { Department of Economics } \\
\text { Bendheim Center for Finance } \\
\text { Princeton, NJ } 08450 \\
\text { and NBER } \\
\text { wxiong@ princeton.edu }\end{array}$ \\
\hline
\end{tabular}


Over the last few decades, behavioral economists have used keen insights from psychology to explain many anomalies in individuals' financial decision making. ${ }^{1}$ As a result of these successes, there are now multiple behavioral biases proposed to explain each anomaly, and the set of proposed behavioral explanations often varies from one anomaly to another. This "zoo" of biases is not satisfying: quantitatively, it is unlikely that they are equally important; and qualitatively, it is possible that a seemingly relevant bias may be just a manifestation of a different yet more fundamental bias. For the field of behavioral economics to eventually arrive at a unified conceptual framework - one that is based on a small set of biases to explain a wide range of phenomena-it is necessary to consolidate the many biases proposed for each anomaly. ${ }^{2}$

This consolidation task is challenging because existing explanations, by design, share similar or identical predictions for a targeted anomaly. Therefore, key moments in observational data may not differentiate one from the others. Some explanations may offer unique predictions along more subtle dimensions, but testing such predictions often requires particular data that are difficult to collect. Comparing the relative importance of different explanations is even more demanding as it requires empirical proxies of different explanations in the same data sample.

Choi and Robertson (2020) adopt a survey-based approach to directly compare many factors that may affect investment decisions. Specifically, they administer a survey to elicit individual responses to an exhaustive list of economic mechanisms ranging from expectations and risk concerns to biases and transactional factors. Survey responses make it possible to rank the relevance of these factors. Despite the appeal, surveys also raise some methodological concerns due to their subjective nature: respondents may not truthfully report their answers and, even when they do, their subjective responses are noisy and may be influenced by the wording and framing of the questions (Bertrand and Mullainathan 2001). Such question-specific biases may distort the ranking of survey responses and lead to spurious conclusions.

In this paper, we propose a new approach to consolidate the bias zoo. Like Choi and Robertson (2020), we also design and administer a survey to elicit individual responses to an exhaustive list of behavioral biases. However, we depart from their purely survey-based approach by using subjective survey responses to explain respondents' actual investment behaviors. This integrated

\footnotetext{
${ }^{1}$ See Barber and Odean (2013), Hirshleifer (2015), and Barberis (2018) for recent literature reviews.

${ }^{2}$ This effort can be thought of as a response to the "lack-of-discipline critique" about behavioral finance that was common in the 1990s, which said that because people may depart from full rationality in various ways, it is too easy to pick biases for a given anomaly by flipping through the pages of a psychology textbook (Fama 1998).
} 
approach enables us to overcome some of the challenges faced by the existing approaches that are based on either observational data or survey responses alone.

The first advantage of our approach is that, by collecting people's attitudes towards a variety of economic mechanisms, it allows us to conduct an apples-to-apples comparison of their explanatory power for the targeted anomaly. This advantage is similar to the purely survey-based approach in Choi and Robertson (2020) and overcomes the difficulty faced by using observational data alone when differentiating multiple explanations that are observationally equivalent. Second, because the targeted anomaly is measured using field data rather than survey responses, our subject of interest is immune from noise introduced through surveys. This avoids biases that arise when survey responses are used for both dependent variables and independent variables, in which case correlated measurement errors on both sides of the regression can significantly bias the coefficients (Bertrand and Mullainathan 2001). Third, by regressing observational outcomes on survey responses at the individual level, the regression coefficients are not affected by question-specific biases arising from misunderstanding or prejudice. That is, a common bias in survey responses favoring a certain factor-potentially due to the survey's choice of words or framing of questions - does not affect the cross-sectional explanatory power of that factor, even though the common bias may distort the ranking of the factor relative to other factors purely based on survey responses.

We illustrate this integrated approach with an attempt to resolve the so-called "excessive trading puzzle.” Initially documented by Odean (1999) and Barber and Odean (2000) for U.S. retail investors and later found to be prevalent across many markets, the puzzle is characterized by three robust facts about retail investor behavior: 1) they perform poorly relative to the market index before fees, 2) transaction costs make their performance even worse, and 3) those who trade more often perform worse. The literature has proposed several behavioral explanations, for example, overconfidence, realization utility, gambling preference, sensation seeking, social interaction, and low financial literacy, on top of standard arguments such as portfolio rebalancing and liquidity needs (see Table 1 for a complete list of the explanations along with the references).

We ran a nationwide survey among Chinese retail investors, with respondents randomized across regions and brokers. As of the end of 2018, the Chinese equity market stood as the second largest in the world. As highlighted by Allen et al. (2020), one of the most striking features of the Chinese stock market is the coexistence of low returns and high trading volume, with more than 
$80 \%$ of total trading volume coming from retail investors. To understand this phenomenon, our survey asked a series of questions related to financial literacy and return expectations, and, most importantly, included an exhaustive list of behavioral biases and motives as potential explanations of excessive trading. The survey took place in September 2018 and received responses from more than 10,000 investors. We then merged these responses with account-level transaction data from the Shenzhen Stock Exchange.

We conduct three sets of exercises that elucidate our approach. In the first set of exercises, we show that, by and large, there is robust statistical consistency between what people say and what they $d o$ : survey responses are largely in line with the actual trading patterns they are designed to capture. For the four trading motives that can be directly matched with our observational data, we find the following: 1) survey-based measures of gambling preference explain the tendency to buy lottery-like stocks, 2) survey-based measures of extrapolation explain the tendency to buy stocks with positive recent returns, 3) survey-based measures of risk aversion explain the holding of stocks with greater volatility, and 4) survey-based return expectations explain changes in stock holdings. By demonstrating this consistency for a wide range of question, we provide external support for prior studies that test finance theories based on surveys alone.

In our second set of exercises, we illustrate how our approach can be used to tame the bias zoo. In the first step, we first run a series of cross-sectional regressions of turnover on each trading motive alone. These regressions confirm that many of the previous explanations for excessive trading also hold true in our sample. In the second step, we include all survey-based trading motives as regressors to compare their explanatory power in a horse race.

Our findings from these exercises are three-fold. First, two trading motives stand out in the horse race as the dominant drivers of excessive trading: gambling preference and perceived information advantage. Explanatory power is sizable for both trading motives: while the standard deviation of the monthly turnover rate in our sample is $123 \%$, gambling preference can explain up to $21 \%$ and perceived information advantage can explain up to $24 \%$. Despite their substantial cross-sectional explanatory power, these two motives are only supported by $37 \%$ and $18 \%$ of the respondents, respectively, much lower than several other motives in the survey with supporting rates over $60 \%$. This contrast highlights the important difference between the cross-sectional explanatory power of survey responses and the simple ranking of survey responses, possibly due to the presence of question-specific biases in the survey. Furthermore, these two motives contribute 
to an annualized transaction fee of $0.6 \%$ and $0.7 \%$, respectively, implying substantial investment consequences borne by investors who display either or both of these trading motives.

Second, for several trading motives, coefficients turn from large and significant in the baseline to small and insignificant in the horse race. For instance, we have constructed two measures of sensation seeking, one for novelty seeking and the other for volatility seeking. While both measures exhibit positive and significant explanatory power in univariate regressions, their explanatory power is largely subsumed by other trading motives in the horse race. In comparison, the explanatory power of both gambling preference and perceived information advantage is robust across various specifications. This apples-to-apples comparison among a large set of behavioral biases is virtually impossible based on observational data alone and allows us to narrow down to a few that are the most important.

Third, in both the baseline regressions and the horse race, we report a number of "null" results. Contrary to popular accounts, low financial literacy, social interaction, and neglect of trading costs do not appear to contribute to more trading in our setting. Perhaps the most consistent, yet surprising set of results concerns neglect of trading costs. Although we have constructed three different measures, none of them explain turnover. Furthermore, in a randomized experiment, we give half of the respondents a "nudge" by having them read a message with pictures illustrating how excessive trading hurts their investment performance due to transaction costs. The treatment group, however, does not exhibit any difference in turnover after the "nudge," leading to a further questioning of the role of neglect of trading costs in driving excessive trading.

In the third and last set of exercises, we compare the effectiveness of transaction-based and survey-based measures of trading motives, by constructing two measures of gambling preference. While the transaction-based measure appears to have greater explanatory power for turnover, it is also correlated with several other trading motives. We therefore conclude by discussing the pros and cons of these two approaches. On the one hand, when carefully designed, surveys can directly target a specific trading motive without being confounded by other trading motives. However, survey responses are subject to measurement noise at the individual level and are thus less powerful. On the other hand, although transaction-based measures are less subject to measurement noise, they may simultaneously capture multiple trading motives and are less reliable in isolating a single economic mechanism. 
Our paper contributes to the growing literature that uses surveys to construct economic variables that are otherwise difficult to measure. Several studies, for example, Dorn and Huberman (2005), Glaser and Weber (2007), and Dorn and Sengmueller (2009), have previously combined survey data with observational data to study the excessive trading puzzle. They focus on one or two behavioral biases or trading motives: risk aversion and perceived financial knowledge in Dorn and Huberman (2005), two forms of overconfidence (overplacement and miscalibration) in Glaser and Weber (2007), and sensation seeking in Dorn and Sengmueller (2009). Our study expands the idea of combining survey responses with observational data by running a horse race of multiple trading motives. In the absence of such a horse race, significant effects associated with one motive may simply reflect other motives, as in the case of sensation seeking in our analysis. Furthermore, by showing consistency between survey-based trading motives and observed trading behaviors, we provide external validation to the survey responses in our sample.

Another strand of the literature, for example, Greenwood and Shleifer (2014), Barberis et al. (2018), and Giglio et al. (2020), uses survey-based expectations to analyze people's belief dynamics. Similar to our paper, Giglio et al. (2020) combine survey expectations with mutual fund holdings data to validate the consistency between survey expectations and actual investments. In other related studies, Chinco, Hartzmark and Sussman (2020) use surveys to uncover subjective perception of consumption risk in investors' portfolio choice decisions, while Epper et al. (2020) use experiments to measure the time discount rate and examine its relationship to wealth accumulation over time. These studies again tend to focus on a single variable or bias. In this regard, our paper is most closely related to Choi and Robertson (2020), who also use survey responses to compare a large number of potentially relevant factors for investment decisions. Employing a different framework by combining survey responses with observational data, our study not only provides external validation to survey responses but also overcomes questionspecific biases, which may distort the simple ranking of survey responses.

The rest of the paper is organized as follows. In Section 1, we explain the survey design and report some stylized facts about Chinese investors from the survey. In Section 2, we validate survey responses using actual trading data, compare survey-based trading motives in a horse race, and discuss the implications of these results. In Section 3, we compare survey-based and transaction-based measures. We conclude in Section 4. We also report detailed information about the survey and additional analysis in an Online Appendix. 


\section{The Survey}

In this section, we first discuss the survey design to further elaborate, from an econometric point of view, the advantages of our approach and the concerns that may arise in our framework. We then explain the procedure for survey distribution and data collection. Finally, we summarize some basic facts from the survey.

\subsection{Survey Design}

We designed the survey to test and differentiate a large set of trading motives developed by the literature. Table 1 provides a summary of all the trading motives we consider. A trading motive may take several forms. For instance, overconfidence comes in at least three forms. The first is overplacement, which means that people have overly rosy views of their abilities relative to others. The second is miscalibration of uncertainty, which means people are too confident in the accuracy of their beliefs. The third is perceived information advantage, which means that people believe they have superior information over others. The survey included at least one question for each form of overconfidence, as detailed in Sections 1 and 2 of the Online Appendix.

In our research design, we first survey a pool of investors about their trading motives and then compare the different motives' explanatory power for an actual trading behavior. Specifically, we consider a standard linear model to relate investor turnover $y$ to a list of trading motives $x_{1}, \ldots, x_{K}$ :

$$
y^{i}=\beta_{0}+\beta_{1} \tilde{x}_{1}^{i}+\cdots+\beta_{K} \tilde{x}_{K}^{i}+\varepsilon_{i},
$$

where $i$ indexes individuals. Surveys allow us to collect noisy measures of the trading motives $\left\{\tilde{x}_{k}^{i}\right\}$, where $\tilde{x}_{k}^{i}=x_{k}^{i}+u_{k}^{i}$ with $u_{k}^{i}$ representing the measurement error of variable $x_{k}$ induced through the survey. In our approach, we do not rank the trading motives by the values of their noisy measures $\left\{\tilde{x}_{k}^{i}\right\}$, but instead by their cross-sectional explanatory power $\left\{\beta_{k}\right\}$ for the observed turnover. Many respondents may agree with a particular trading motive, but we can confirm its relevance only if we also observe that these respondents trade more than other respondents.

A first advantage of our approach is that by directly observing dependent variable $y$ from transaction data, we can avoid spurious coefficients due to mismeasurement in dependent variables. To see why, suppose that instead we use survey-based measure $\tilde{y}^{i}$, where $\tilde{y}^{i}=y^{i}+\delta^{i}$ and $\delta^{i}$ reflects the survey-induced measurement error in $y^{i}$. In our analysis, this corresponds to using self- 
reported turnover rather than actual turnover. When $\delta^{i}$ is white noise and uncorrelated with $x_{k}^{i}$, the OLS coefficients will not be biased. However, as discussed by Bertrand and Mullainathan (2001), if measurement error $\delta^{i}$ is correlated with $x_{k}$, which is highly likely, OLS coefficients can be severely biased. For example, it may be more difficult for overconfident investors to recall bad trading experience in the past, resulting in a negative bias $\left(\delta^{i}\right)$ in the self-reported turnover rate. If we use overconfidence as an explanatory variable $x_{k}$, coefficient $\beta_{k}$ can be substantially biased downward due to the negative correlation between $x_{k}$ and $\delta$.

A second advantage of our approach is that question-specific biases in the measurement of $x_{k}$ will not bias the OLS coefficients. Suppose that $u_{k}^{i}=u_{k}+\eta_{k}^{i}$, where $u_{k} \neq 0$ and $\eta_{k}^{i}$ is pure white noise. For instance, if a trading motive is poorly phrased and subsequently invites misperception or prejudice, there is a question-specific bias $u_{k}$ against that motive among all survey respondents. This bias reduces the mean of the survey responses $\tilde{x}_{k}^{i}$ and thus may distort the ranking of the motive relative to other motives in the purely survey-based approach used by Choi and Robertson (2020). ${ }^{3}$ In contrast, in the cross-sectional regression (1), the question-specific bias $u_{k}$ will not bias the OLS estimate of $\beta_{k}$, as the bias will be absorbed by the intercept. Therefore, when a question is poorly worded and generates, on average, less-favorable responses from the respondents, it will not bias the OLS estimation as long as the downward bias is common to all respondents and does not interact with individual characteristics that we do not control for.

Although our approach is not subject to question-specific measurement bias, other measurement issues may still arise. We now discuss their implications and our solutions.

\section{White noise}

We start with $\eta_{k}^{i}$, the white noise component in the measurement error. This component will produce an attenuation bias in the estimate of the regression coefficients $\beta_{k}$. The magnitude of this bias may differ across motives, depending on the variance-covariance matrix of the $K$ explanatory variables and the variance of each type of white noise. For instance, a larger variance of white noise contributes a greater attenuation bias, which leads to the common concern that insignificant

\footnotetext{
${ }^{3}$ More precisely, Choi and Robertson (2020) asked respondents in their survey to rank competing mechanisms specifically for a given decision variable, that is, the $y$ variable in equation (1). Therefore, an alternative way to interpret their survey responses is that the responses may already capture the respondents' own estimates of the beta coefficients, $\beta_{k}$. In our view, this interpretation may further complicate the task assigned to the respondents and result in other sources of bias due to the more complex inference process.
} 
results from horse races may simply reflect a lot of white noise. To the extent that white noise in measurement errors makes it more difficult to detect significant factors, any significant factor from our analysis is even more important in practice.

\section{Wording, scaling, and mental effort}

Measurement errors could also arise due to the wording of questions and scaling of answer options. For example, people give rather different answers to the following two questions: "Do you think the United States should forbid public speeches against democracy?" and "Do you think that the United States should allow public speeches against democracy?" Similarly, when the scaling of answer options changes, subjects may report their answers differently as they might be anchored by the choice of options. Lack of mental effort typically makes these issues worse, as subjects may not read the questions in detail and choose answers that appear first or last in the list of options. As discussed above, when wording or scaling induces a question-specific bias, it will be absorbed by the intercept and will not bias the OLS coefficients. When the bias is individualspecific and more prevalent in certain demographic groups, then individual characteristics should be properly accounted for. In our main regressions, we control for an exhaustive list of demographic variables.

To mitigate biases induced by wording, we adopt a jargon-free protocol. We phrased the questions as accurately as possible when describing the underlying concept while ensuring that they remained comprehensible to the average respondent. To confirm that respondents could immediately understand each question, we ran a series of pilot tests among the general population on a Chinese version of Mechanical Turk and solicited their feedback on the survey design. The overwhelming majority of respondents found the questions easy to understand. This also ensures that subjects typically did not find it mentally burdensome to complete the survey.

To deal with biases induced by scaling, we designed all questions to be multiple choice with a standardized menu of answer options. There are two types of qualitative questions. The first type - "agreement" - asked respondents whether they agree or disagree with a statement that describes a particular motive driving trading decisions. Answer options included: "strongly agree," "agree," "neutral," "disagree," "strongly disagree," "do not know," and "decline to answer." The second type - "frequency" - asked respondents how often they consider a particular motive when they trade. Answer options included: "always," "often," "sometimes," "rarely," "never," "do not 
know," and "decline to answer." We also sought quantitative answers for certain trading motives (e.g., estimates of transaction fees to measure neglect of trading costs). In such cases, we provided several options, each covering a specific value range. The standardization of answer options ensured that any bias resulting from the design of answer options should be small and consistent across all the questions.

\section{Attitudes}

Survey questions typically elicit people' attitudes toward a certain description or statement. However, a clear attitude may not exist, and if forced to give an answer, people may just randomly pick an answer, causing further noise in measurement. To deal with this "no-attitude" issue, we include two answer options - "do not know" and "decline to answer"- so that respondents do not feel compelled to give an answer when they do not have a clear one in mind.

\section{Social desirability}

Another concern, particularly relevant to eliciting biases and mistakes, is that respondents may want to look good in front of others and avoid giving answers that may sound stupid or wrong. This concern arises naturally in interview-based surveys, in which respondents directly interact with the interviewer. Since our survey was conducted online, our respondents had less of a need to appear socially desirable. Moreover, we carefully phrased the questions to be objective and avoided making any inference about a certain behavior being right or wrong. For instance, to elicit a measure of overconfidence, instead of asking "How overconfident do you think you are?" we asked respondents to only self-assess their investment performance. Later, we would compare it to their actual performance to get our measures of overconfidence.

\section{Others}

We discuss three final considerations in our survey design. First, survey responses are subjective: they capture how people consciously perceive themselves to be making investment decisions. ${ }^{4}$ A common criticism of subjective surveys in economic analysis is the "as if" critique: respondents may not consciously perceive a factor to be important, but they still behave as if it

\footnotetext{
${ }^{4}$ In the language of Adam Smith, respondents are effectively asked to act as the "impartial spectators" to evaluate the reasons and drivers behind their own decisions (Grampp 1948).
} 
were (Friedman 1953). However, subjective perceptions are still useful for many reasons: they shed light on the true decision making process, they help differentiate competing theories, and they have predictive power for implications of debiasing mechanisms on individuals' future behaviors (Choi and Robertson 2020). It is also inherently interesting to know about people's subjective reasoning. We add that subjective perceptions are also relevant for nudge interventions: if a nudge is targeting a bias that people are not even aware of, it is unlikely that the intervention would successfully produce the desired outcome (DellaVigna and Linos 2020).

Second, at a general level, there is a significant tradeoff between "being rigorous" and "being intuitive" in the design of survey questions. To be fully rigorous in investigating trading motives, the corresponding survey questions needed to comprehensively capture all their aspects. For instance, to fully grasp realization utility requires calibrating a utility function that captures not only the different attitudes between gains and losses but also the shape of the utility function in different regions. Such a design would make the survey exceedingly long and unavoidably include academic jargon, which, as discussed above, would immediately raise issues on wording and mental efforts. The psychology literature also documents an attribute substitution bias, whereby participants may not respond to complicated questions but rather answer a related question that is easier to respond to (Kahneman and Frederick 2002). In light of these concerns, we used the "being intuitive" design to make the phrasing as intuitive as possible to laypeople.

Third, post-survey, we designed our empirical strategy with the aforementioned measurement issues in mind. First, we validated survey responses with actual trading behavior and found strong consistency between survey responses and transaction data. This provides further validation of our survey design. Second, we encoded all survey-based trading motives into dummy variables. This standardization minimizes the variation of measurement errors across all survey-based trading motives and facilitates an apples-to-apples comparison.

The final survey contained four main parts. The first part contained eight questions measuring financial literacy. These questions included the classic "big three" questions as well as several other widely used questions to measure financial literacy (Lusardi and Mitchell 2007, 2011). At the end of this section, we also asked respondents to assess how many questions they answered correctly. This allowed us to construct a measure for overconfidence based on financial literacy. The second part represented the core of the survey, in which we asked respondents to answer a 
series of questions related to various trading motives. We postpone a more detailed discussion of this part to Section 1.3. The third part asked about basic demographic characteristics, including name, gender, date of birth, province, city, education, income, net worth, phone number, brokerage firm, and broker branch. While many of these variables serve as control variables in subsequent analysis, they also provide crucial identifying information that enabled us to locate each correspondent in the transaction database. Finally, for a randomly selected group of respondents (the treatment group), we also included a fourth "nudge" section. We explain the "nudge" and discuss the results in more detail in Section 2.8.

\subsection{Data}

We administered the survey through the Investor Education Center of the Shenzhen Stock Exchange (SZSE). As part of its regular operations, the Investor Education Center annually surveys domestic retail investors to assess their financial literacy and trading motives. In 2018, we began to collaborate with the center to redesign the survey with the aforementioned research question in mind. Our target sample size was 10,000 investors, a size that provides sufficient statistical power and was feasible to implement. To ensure that the survey sample was nationally representative, we randomized across branch offices of China's ten largest brokers. Specifically, we selected 500 branch offices across 29 provinces (and regions) and required each branch office to collect at least 20 valid responses. The number of branch offices allocated to each province (region) was proportional to the total trading volume from that province (region) in 2017.

The survey took place in September 2018, and respondents were given two weeks to complete the survey. ${ }^{5}$ A valid response had to be completed within 30 minutes. Respondents could open the survey using their personal computers or their smartphones. ${ }^{6}$ We collected an initial sample of 12,856 respondents. We report the distribution of respondents across brokers and provinces in Table A1 of the Online Appendix. By design, respondents are evenly distributed across the ten

\footnotetext{
${ }^{5}$ The SZSE Center first distributed the survey link to each broker's headquarter. The headquarter then redistributed it to the preselected branches, after which local client managers would send the survey to their clients (investors), likely via phone calls or WeChat messages. Once an investor had completed the survey, the manager would record the investor's name, phone number, and branch name. This information was then sent back to us for verification purposes.

${ }^{6}$ To boost the response rate, we included the logos of both the SZSE and the Shenzhen Finance Institute on the front page of the survey. We also explicitly included a confidentiality agreement to make respondents feel more secure about their answers. Finally, we used monetary rewards as incentives. Specifically, among those who completed the survey, 20 would be randomly selected to receive a gift card worth 500 RMB (around 80 USD) and 1000 would receive a gift card worth 50 RMB (around 8 USD).
} 
brokers, with only slight variation. In terms of geographic variation, areas that are more financially developed (e.g., Guangdong, Zhejiang, Jiangsu, and Shanghai) are more represented in our sample.

Table 2 reports a more detailed summary of the sample's demographic characteristics. Overall, the sample is balanced in gender and highly educated: more than half of the respondents had a college or higher degree. Respondents were primarily middle-aged: about half of the sample were aged between 30 and 50. They were also quite wealthy: the median annual income was around 200,000 RMB and the median household net worth was around 500,000 RMB. Overall, our sample represents a relatively well-educated, wealthy set of retail investors, and this means that any results we find should not be simply interpreted as an average effect. Instead, to the extent that rich and sophisticated investors are less affected by behavioral biases in their investment decision making, our results may serve as a lower bound.

Finally, while we feel confident that the use of monetary incentives and the brand names of our respective institutions should invite high-quality responses, we cannot avoid having a few respondents who quickly clicked through the survey without spending much time on the questions, especially given the survey's large scale. We eliminate these responses by examining the total amount of time spent on the survey. We show, in Figure A2 of the Online Appendix, that it took a median respondent about eight minutes to complete the survey and $95 \%$ of respondents finished within 20 minutes. Respondents who spent less than three minutes on the survey experienced a sharp drop in their financial literacy score, suggesting that they may have shirked during the survey. In subsequent analysis, we dropped these observations, which reduced our sample size to 11,268.

\subsection{Survey Results}

We now summarize the questions covered in the survey and their responses. Our empirical strategy is not to rank trading motives by their supportive rates but to compare their explanatory power for actual turnover in a cross-sectional regression. Nevertheless, it is useful to have an overall picture of the survey responses.

\section{Financial literacy}

Table 3 reports the summary statistics for the eight questions on financial literacy. In addition to the classic "big three" questions on interest rates, inflation, and diversification (Lusardi and Mitchell 2014), we also included five other questions to capture additional dimensions of financial 
(or investment) literacy. ${ }^{7}$ Panel A shows that, out of all eight questions, seven have a correct rate above $75 \%$. The only exception is the question about the relationship between interest rates and bond prices. Panel B shows that more than $80 \%$ of the respondents correctly answered at least six questions. In fact, one-third of them were correct on all eight questions. Panel B also shows the distribution of self-assessed scores, which is similar to that of the actual scores. Overall, investors in our sample display a high level of financial literacy. ${ }^{8}$

\section{Overconfidence}

Overconfidence is an important concept in behavioral finance and has been adopted by various models to explain a wide range of anomalies in financial markets, including excessive trading, use of leverage, price momentum and reversals, and asset bubbles. ${ }^{9}$ The literature also suggests that overconfidence may be present in several closely related, albeit distinct, forms: overplacement of ability, miscalibration of uncertainty, and overprecision of information. We designed questions to capture each of these forms.

Overplacement of one's own ability is perhaps the most direct form of overconfidence. We constructed two measures of this form, one by the difference between self-assessed and actual performance and the other by the difference between self-assessed and actual literacy scores. ${ }^{10}$ In Table 4, Panel A reports their summary statistics. In constructing overplacement of performance, self-assessed performance is measured by the self-reported rank of investment performance among all investors in 2017 while actual performance is measured by the actual rank in the population. At this point, we have not yet merged survey responses with transaction data, so Panel A only reports the distribution of self-assessed performance. The patterns suggest that respondents are rather optimistic about their performance: almost two-thirds believe that their performance is better than average while only a quarter believe that it is below average. Panel A also reports the second

\footnotetext{
${ }^{7}$ These questions are related to the concept of risks and volatility (Question 4), the definitions of shareholders, the price-to-earnings ratio, and mutual funds (Question 5, 7, and 8), and the relationship between interest rates and bond prices (Question 6).

${ }^{8}$ Lusardi and Mitchell (2014) show that the fraction of respondents who correctly answer all "big three" questions ranges from 3\% (Russia) to 57\% (Germany). In contrast, 70.4\% of investors in our survey correctly answer all "big three" questions. One possible reason is that their surveys typically draw respondents from the general population, whereas ours draws from investors already participating in the stock market.

${ }^{9}$ See, for example, Kyle and Wang (1997), Daniel, Hirshleifer and Subrahmanyam (1998, 2001), Odean (1998), Gervais and Odean (2001), Scheinkman and Xiong (2003), Glaser and Weber (2007), and Barber et al. (2020).

${ }^{10}$ Dorn and Huberman (2005) and Barber et al. (2020) use a similar measure for perceived financial knowledge.
} 
measure, overplacement of literacy. Overall, respondents do not overestimate their financial literacy, which is perhaps not surprising given the sample's overall high level of financial literacy.

Overconfidence may also show up as miscalibration of uncertainty, as suggested by Alpert and Raiffa (1982). ${ }^{11}$ We measure miscalibration of uncertainty by the difference between two estimates: one for upside returns and the other for downside returns. This is based on two questions asking respondents to estimate how much the stock market will go up or down next year with 10\% probability. The difference between the two estimates gives an $80 \%$ confidence interval. The rational benchmark (based on historical market volatility) suggests that this difference should be $76 \%$, but Panel A of Table 4 shows that most respondents report a much narrower range.

Overconfidence may also show up as overprecision about one's own information. We will describe this measure later when we discuss information-related questions.

\section{Extrapolation}

The behavioral finance literature has also emphasized the tendency of investors to extrapolate past returns as a key driver of stock return predictability and excessive trading. ${ }^{12}$ In Table 4, Panel $B$ reports the summary statistics for two questions concerning whether investors form expectations about future returns based on past returns. These two questions elicit investors' extrapolative beliefs in two scenarios. In the first scenario, a stock's price keeps rising, and in the second scenario, a stock's price keeps falling. Respondents are asked whether they believe the stock's price will rise or fall in the future. In both scenarios, more respondents believe in price continuation than reversal, suggesting that Chinese investors on average exhibit extrapolative beliefs.

\section{Neglect of trading costs}

Barber and Odean (2000) and Barber et al. (2009) show that trading causes retail investors in the United States and Taiwan to underperform relative to the overall market, with more than $60 \%$ of underperformance directly due to commissions and transaction taxes. These findings suggest that investors who trade a lot may have neglected the various fees and taxes associated with trading.

\footnotetext{
${ }^{11}$ Ben-David, Graham and Harvey (2013) show that $80 \%$ confidence intervals provided by firm executives for the subsequent year's stock market return only cover $36 \%$ of the realizations, and they use the surveyed confidence interval to measure the executives' overconfidence.

${ }^{12}$ See, for example, Barberis, Shleifer and Vishny (1998), Hong and Stein (1999), Barberis et al. (2015, 2018), and Jin and Sui (2019).
} 
As it is common for financial regulators across the world to use Tobin taxes to curb speculative trading, neglect of trading costs could undermine the effectiveness of such financial policies.

Neglect of trading costs stems from at least two possible sources. The first one is underestimation: investors systematically believe the fee is lower than it actually is, possibly due to lack of financial knowledge. The second one is a lack of salience: even when investors have full knowledge about trading costs, it may still matter very little to their trading because the amount associated with each transaction is small and the concept of trading costs may not come to mind at the time of trading. ${ }^{13}$

To capture these two forms of neglect of trading costs, we constructed three different measures. Panel C of Table 4 reports the summary statistics. First, we directly asked investors to estimate the total transaction costs associated with a round-trip buy and sell at 10,000 RMB. The results show that respondents significantly underestimated trading costs: while, on average, such a round-trip transaction should incur a fee of 15 to $26 \mathrm{RMB}$, almost $70 \%$ of the respondents reported an estimate below the lower bound. The second question asked how often an investor considers transaction costs when trading stocks. Similarly, more than half of the respondents said that they never or rarely do so. The third question targeted the implicit cost of the bid-ask spread by asking whether the respondent agrees that bid-ask spread is a form of trading cost. Around $60 \%$ of respondents agreed while $23 \%$ disagreed. Overall, there is strong evidence that retail investors in China underestimate or neglect trading costs.

If neglect of trading costs is due to (a lack of) salience, then presenting transaction costs in a more salient manner or reminding investors of these costs more frequently may lead them to trade less. To test this hypothesis, we gave half of the respondents a "nudge": we increase the salience of trading costs by presenting them in annualized terms and reminding investors about the negative impact of excessive trading to overall returns. We discuss these results later in Section 2.8.

\section{Gambling preference}

Barberis and Huang (2008) show that the cumulative prospect theory of Tversky and Kahneman (1992) can generate a preference for gambling stocks, meaning stocks with positively

\footnotetext{
${ }^{13}$ Several papers show that manipulating the salience of a stock's purchase price affects the level of the disposition effect (e.g., Frydman and Rangel 2014; Birru 2015; Frydman and Wang 2019). Other papers find that manipulating the salience of taxes affects consumer responsiveness to taxes (e.g., Chetty, Looney and Kroft 2009; Taubinsky and Rees-Jones 2017).
} 
skewed returns. Bordalo, Gennaioli and Shleifer (2012) suggest that salience may cause investors to exaggerate the probability of salient payoffs, also leading to a preference for gambling stocks. ${ }^{14}$ Barber and Odean (2000) argue that if gambling stocks change over time due to fluctuations of volatility and tail distribution, gambling preference may also contribute to excessive trading by leading some investors to chase gambling stocks and thus trade with other investors.

In Table 5, Panel A shows the responses on the two questions about gambling preference. The first question asked whether the respondent aims to select a few blockbuster stocks in order to get rich quickly. The second question asked whether the respondent consciously perceives trading stocks as buying lotteries in that they are willing to exchange small losses for the small probability of a big gain. About one-third of the respondents agreed or strongly agreed with each statement. In what follows, we differentiate these two questions by labeling the first one as representing "blockbusters" and the second one as representing "lotteries."

In phrasing these two questions, we had the following design in mind: the "blockbusters" question focuses on the salient upside and deliberately tones down the fact that "blockbusters" are rare. Therefore, investors who agree with this statement are the ones drawn to the large upside without necessarily assessing its small probability. In the language of prospect theory, these investors tend to over-weight small probabilities. In contrast, the "lotteries" question contains a direct description of lotteries by explicitly stating that large payoffs rarely happen. Therefore, the two questions not only help identify the gamblers among the respondents, but also help differentiate their assessments of the tail probabilities. As we will show, the "blockbusters" question has substantially stronger explanatory power for investor trading. ${ }^{15}$

\section{Realization utility}

Shefrin and Statman (1985), Odean (1999), Grinblatt and Keloharju (2001), and Grinblatt and Han (2005) argue that trading can arise as a result of the widely observed disposition effect. Barberis and Xiong $(2009,2012)$ and Ingersoll and Jin (2013) formalize theories of realization utility, in which realization utility results in realization utility and contributes to excessive

\footnotetext{
${ }^{14}$ Kumar (2009) and Boyer, Mitton and Vorkink (2010) provide evidence that supports the presence of such gambling preference. Barberis, Jin and Wang (2020) study how prospect theory can explain stock market anomalies.

${ }^{15}$ An alternative explanation for the difference between these two questions is that the "blockbusters" question helps to identify the "impatient" gamblers. As the literature does not offer any link between trading volume and the discount rate, we attribute the question's better explanatory power to incorrect probability assessment rather than to impatience.
} 
trading. ${ }^{16}$ In Table 5, Panel B reports the summary statistics for the two questions on realization utility. Similar to the questions on extrapolative beliefs, these two questions ask respondents to make investment decisions under two hypothetical scenarios. In the first scenario, the respondent is given a stock whose price has gone up since purchase and is then asked which of the two actions would bring more personal happiness: selling the stock or holding on to it. In the second scenario, the respondent instead faces a stock whose price has gone down since purchase and is asked which action would be more painful. According to realization utility, selling winners is more pleasing than holding winners while selling losers is more painful than holding losers. Survey responses for the two questions are mixed. In the first question, consistent with realization utility, more respondents say selling winners makes them happier. In the second question, however, more respondents report that holding on to losers is more painful than selling losers. In what follows, we differentiate these two questions by labeling the first question as realization utility for winners and the second question as realization utility for losers.

\section{Sensation seeking}

Sensation seeking, a measurable psychological trait linked to gambling, risky driving, drug abuse, and a host of other behaviors, is shown to be an important motivation for trading (Grinblatt and Keloharju 2009; Dorn and Sengmueller 2009). ${ }^{17}$ We designed two questions to capture two distinct dimensions of sensation seeking: novelty seeking, which says that people derive utility from doing something new, and volatility seeking, which says that people derive utility from doing something risky. In Table 5, Panel C reports the summary statistics for these two questions. Overall, answers to these two questions exhibit a similar distribution, but the respondents in general do not exhibit a strong tendency for sensation seeking.

\section{Information}

Economists have long argued that access to private information is a key reason for investors to trade in financial markets. However, the classic no-trade theorem posits that when all investors are rational and share the same prior beliefs, asymmetric information cannot cause them to trade due to the concern of adverse selection (Milgrom and Stokey 1982). Instead, theories of financial

\footnotetext{
${ }^{16}$ Frydman et al. (2014) provide neural evidence to support realization utility in financial decision making.

${ }^{17}$ Brown et al. (2018) further argue that sensation seeking may even affect the trading of hedge fund managers.
} 
market trading with asymmetric information, for example, Grossman and Stiglitz (1980) and Kyle (1985), typically involve the presence of noise traders, who may trade at losses, so that rational traders may trade despite the potential concern of adverse selection.

Are retail investors in China rational investors with a genuine information advantage or noise traders who believe they hold superior information even though they do not? We included two questions in the survey to elicit a respondent's perception of their information advantage. The first question measures one's belief in having an information advantage by asking how often they believes they know stocks better than other investors. A positive response to this question may be associated with a genuine information advantage, but it could also reflect a misperceived information advantage due to overconfidence. This latter possibility potentially reflects a tendency to exaggerate one's own information but not the information of others. Various theoretical models have used this tendency to specify investor overconfidence, the third form of overconfidence that we mentioned earlier. ${ }^{18}$ Later, we differentiate a genuine information advantage from a misperceived one by examining whether the respondent actually performs better.

The second question measures one's potential adverse selection concerns by asking how often they worry that others know stocks better than themselves. This question measures dismissiveness of others' information, a form of investor bias that offers distinct implications from overconfidence for equilibrium prices and trading volume (Eyster, Rabin and Vayanos 2019). Panel A of Table 6 shows that about $18 \%$ of the respondents say that they often or always believe they have an information advantage while $47 \%$ of the respondents never or rarely believe that they face an information disadvantage. Despite the relatively small fraction of respondents who indicate a perceived information advantage, they indeed trade more than others, as we will show later.

\section{Social interaction}

Shiller (1984) argues that investing in speculative assets is a social activity because investors enjoy discussing investments and gossiping about others' investment successes or failures. As a result, social influences could lead to excessive trading. ${ }^{19}$ We designed two questions to capture

\footnotetext{
${ }^{18}$ For example, Kyle and Wang (1997), Odean (1998), Gervais and Odean (2001), and Scheinkman and Xiong (2003) all model overconfidence as stemming from a perceived information advantage.

${ }^{19}$ Hong, Kubik and Stein (2004) provide evidence that stock market participation is influenced by social interaction. Han, Hirshleifer and Walden (2020) develop a model to show that social interaction exacerbates excessive trading among investors.
} 
social interactions, one about the influence of family, friends, and other acquaintances, and the other about the influence of investment advisors. Panel B of Table 6 shows that around 14\% of the respondents say that they are often or always influenced by family, friends, or other acquaintances while $8 \%$ say their investment advisors often or always have an influence on their trading.

\section{Other trading motives}

In Table 6, Panel $\mathrm{C}$ reports the responses on the two questions related to liquidity needs and rebalancing motives. Overall, only about $11 \%$ of the respondents say portfolio rebalancing often or always affects their trading, whereas about $17 \%$ say liquidity needs often or always affect their

trading. Consistent with prior literature, retail investors do not appear to be considering these rational trading motives in their day-to-day trading activities.

Panel D of Table 6 reports three standard questions for measuring risk aversion. We elicit investors' risk attitude by asking whether they would be willing to give up their current stable jobs for other jobs with higher expected income but also higher uncertainty in three hypothetical scenarios. While about $34 \%$ of the investors were unwilling to take the job with the smallest risk, $26 \%$ of the investors were willing to take the riskiest job.

\section{Comparison with U.S. investors}

While our study primarily focuses on Chinese retail investors, it is of general interest to know how U.S. retail investors, who are often believed to be more sophisticated than their Chinese counterparts, would respond to our survey. We translated the original survey into English with slight modifications (tailored to American investors) and ran the survey on Mechanical Turk among a smaller sample of 400 U.S. retail investors. On the one hand, we find that U.S. investors care more about trading costs, rely more on investment advisors, and are more alert to being at an information disadvantage. These differences may be attributed to the institutional environment of the U.S. stock market: higher transaction fees charged by brokers, the popularity of investment advisors, and a highly institutionalized investor base. On the other hand, contrary to conventional wisdom, U.S. retail investors exhibit stronger biases on several fronts: they are more subject to realization utility, display a stronger preference for gambling, and are more prone to sensation seeking. We offer a more detailed discussion of these differences in Table A3 of the Online Appendix. 


\section{A Horse Race Based on Survey Responses}

In this section, we use survey responses to differentiate various explanations for the excessive trading puzzle. We start by merging the respondents' survey responses with their transaction data. We demonstrate the external validity of survey responses by showing their ability to capture actual trading behaviors. We examine the explanatory power of each trading motive alone for turnover, followed by a horse race among all survey-based trading motives. We also provide some robustness checks and additional evidence for several key motives at the end of the section.

\subsection{Merging Surveys with Transactions}

In the third part of our survey, we asked respondents to provide information on various demographic variables, including name, date of birth, broker name, and branch name. This allows us to uniquely identify a substantial fraction of the respondents in the transaction database of the Shenzhen Stock Exchange. Specifically, out of the 11,268 respondents that remain in our sample, we can uniquely identify 6,013 investors. Our transaction data cover January 2018 through June 2019, which nicely staddles our survey date of September 2018. We further require an investor to have held at least one stock in the Shenzhen Stock Exchange during the two-year window before the survey. ${ }^{20}$ This further reduces the sample size to 4,671, which is our main sample. Table 2 shows that investor characteristics are comparable between all the respondents and those in the main sample, suggesting that the merging process does not induce further biases.

Is the excessive trading prevalent among investors in our sample? Table 7 reports the summary statistics of the monthly turnover and portfolio return for the post-survey sample from October 2018 through June 2019, that is, the nine-month window after the survey. When needed, however, we also extend the window to cover the nine months before the survey. Table 7 confirms the existence of excessive trading. First, investors trade intensively: the median monthly turnover rate is almost one, suggesting that they fully reshuffle their portfolios almost once every month. Second, their performance is poor: while the monthly return of the Shenzhen Composite Index was about $0.6 \%$ from October 2018 through June 2019, the median net return in our sample is $0.0 \%$. Third, those who trade more perform worse: the correlation between turnover and raw returns is -0.07

\footnotetext{
${ }^{20}$ An investor may have been invited to take our survey without any stockholding in the Shenzhen Stock Exchange due to various reasons: holding mutual funds or ETFs, or holding stocks listed on the Shanghai Stock Exchange.
} 
while the correlation between turnover and net returns is -0.16 . These negative correlations are statistically significant and confirm the key findings of Odean (1999) and Barber and Odean (2000).

\subsection{Encoding Survey-based Variables}

To make different survey-based variables comparable, we encode them into dummy variables. A detailed description of the construction of these dummy variables is in Table A2 of the Online Appendix. In a nutshell, for the "agreement" type of questions, we code "strongly agree" and "agree" as 1 and other answers as 0; for the "frequency" type of questions, we code "always" and "often" as 1 and other answers as 0 ; for quantitative questions, we typically use zero as the cut-off value. ${ }^{21}$ Table 8 reports the summary statistics of these dummy variables and their pairwise correlations. Note that for the multiple questions targeting the same trading motive, their pairwise correlation, highlighted in bold, is generally high, which suggests that their responses are internally consistent.

A high supporting rate in the survey for a certain trading motive does not necessarily mean that this motive is a key determinant of excess trading, due to the potential presence of questionspecific biases induced by the survey. We filter out such biases by examining the cross-sectional explanatory power of survey responses for actual turnover in the aforementioned regression framework. Only when variation in the survey responses of a given motive explains the crosssectional variation in turnover can we conclude that the motive is relevant to excessive trading. Column (1) of Table 8 shows the degree to which each trading motive is supported by the respondents in our survey. Several motives, such as overplacement of performance, miscalibration, and underestimation of transaction costs, have strong supporting rates above $60 \%$. Interestingly, as we will show, these motives do not have the strongest explanatory power for turnover in the cross-section, possibly because these survey questions are easier for the respondents to understand. In contrast, some other motives such as gambling preference for blockbusters and perceived information advantage have substantially stronger explanatory power, despite their lower rankings indicated by the values in column (1).

\footnotetext{
${ }^{21}$ The only exception is when we code the question of dismissiveness, where we code "never" or "rarely" as 1 and others as 0 .
} 


\subsection{Validating Survey Responses}

There are several widely held concerns about the use of survey responses in testing economic hypotheses. First, respondents may not take the survey seriously and may not truthfully report what they really think or believe. Second, even if their responses are truthful, they may not act in a way that is consistent with their responses. Indeed, because most existing papers are limited to the use of either survey data or transaction data only, the literature is still missing a systematic test of the external validity of subjective survey responses from investors. ${ }^{22}$

Ideally, we would like to validate responses to all the questions asked in the survey, but this is not plausible. For instance, although the survey has several questions regarding the sources of information and the influence of social interactions, it is difficult, if not impossible, to infer these aspects from observational data without collecting additional data and making strong assumptions. Given these limitations, we validate survey responses for a set of four questions with natural empirical counterparts that can be directly constructed from transactions. These questions concern extrapolation, gambling preference, risk aversion, and return expectation. In addition to having straightforward implications about trading behaviors, these questions span a wide range of trading motives: belief formation, preferences, and return expectations. For brevity, we focus on gambling preference in the main text. We briefly talk about other validation exercises with their details included in Section 8 of the Online Appendix. ${ }^{23}$

\section{Gambling preference}

We start by measuring gambling behavior from transaction data. Gambling preference motivates investors to buy assets with positively skewed returns. While it seems straightforward to measure gambling behavior based on return skewness, the literature, for example, Kumar (2009),

\footnotetext{
${ }^{22}$ Several earlier examples of such validation exercises are worth noting. Using survey and administrative data from Denmark and Sweden, respectively, Koijen, Van Nieuwerburgh and Vestman (2015) and Kreiner, Lassen and LethPetersen (2015) show that, while survey-based consumption is noisy at the individual level, it is consistent with actual consumption measured from administrative data. More recently, Giglio et al. (2020) examine the relationship between survey expectations and mutual fund holdings and find that survey expectations are consistent with respondents' mutual fund holdings. Compared to these earlier papers that study consumption and expectation, our main interest is to validate whether survey-based trading motives reflect investors' actual trading behavior.

${ }^{23}$ Note that while we demonstrate consistency between survey responses and trading behaviors, we do not claim that the targeted trading behavior is solely captured by the designed question. Indeed, as we will show later in Section 3, one type of observed behavior (such as purchase of gambling stocks) can be driven by multiple motives. Therefore, the purpose of our validation exercise is simply to demonstrate the relevance and usefulness of survey responses.
} 
argues that return skewness is difficult to compute and is not a metric sufficiently intuitive to investors. Instead, salient stock characteristics such as realizations of extreme returns would attract investors with a gambling preference. This argument is particularly compelling as it connects well with our earlier discussion of gambling preference driven by investors' over-weighting of tail outcomes (Barberis and Huang 2008; Bordalo, Gennaioli and Shleifer 2012). Motivated by this argument, we take advantage of a unique regulation in the Chinese stock market: the daily price limits rule. This rule states that daily stock returns of individual stocks cannot exceed $10 \%$. We use the total count of up-limit hits (i.e., the number of days with prices hitting the up limit) in a preceding period to proxy for a stock's positive return skewness. As hitting the daily up limit puts a stock in the headlines of the stock exchange, this event is highly salient and attracts attention from investors. Thus, we measure an investor's gambling behavior by the volume-weighted count of up-limit hits over either a month or a quarter based on all the stocks they added to the portfolio.

Table 9 reports the results when regressing transaction-based gambling behavior on surveybased gambling preference. Panel A uses the total count of up-limit hits over the preceding onemonth horizon, while Panel B uses one quarter as the horizon. Recall that we included two survey questions regarding gambling preference, one about the desire to pick blockbusters to get rich and the other about a conscious perception of stocks being lottery-like. Indeed, responses to the first question significantly explain gambling behavior with a positive sign. On average, the stocks they purchase have a larger count of up-limit hits by around $0.1(0.2)$ times in the preceding month (quarter), and this relationship holds in both the pre-survey and post-survey periods. Interestingly, responses to the second question do not explain gambling behavior. We document a similar pattern about their explanatory power on turnover later.

\section{Extrapolation, risk aversion and survey expectations}

We perform three additional exercises to validate survey-based measures of extrapolative beliefs, risk aversion, and return expectations, using a method similar to before. The results are reported in Tables A5 to A7 of the Online Appendix. First, investors who report having extrapolative beliefs exhibit stronger extrapolative behavior: on average, the stocks they purchase experience $1 \%$ higher returns in the preceding month and more than $2 \%$ higher returns in the preceding quarter, and this holds in both pre-survey and post-survey samples. Second, consistent with Dorn and Huberman (2005), survey-based measures of risk aversion are negatively associated 
with holding more-volatile stocks. Third, consistent with Giglio et al. (2020), survey-based expectations about future stock market returns are positively associated with an increase in stock holdings, but the magnitude, as noted by Giglio et al. (2020), is relatively small.

Finally, we note that throughout the validation exercises, although the coefficient between the survey response and the targeted trading behavior is highly significant, the $R$-squared is generally small. For instance, in Table 9, across all specifications, the $t$-statistic for gambling preference (blockbusters) remains around 4 , but the $R$-squared is consistently below $2.5 \%$. This suggests that although survey responses are consistent with the targeted behavior, much of its variation is left unexplained. This low $R$-squared could be due to measurement errors in survey responses, but it could also be that the behavior itself is driven simultaneously by multiple factors. We will discuss this important issue further in Section 3.

\subsection{Baseline Results on Turnover}

After validating survey responses, we proceed to examine the relationship between surveybased trading motives and turnover. We primarily focus on using survey responses to explain postsurvey turnover. ${ }^{24}$ Table 10 presents the baseline results, where in each column we regress turnover on a particular survey-based trading motive. Most regressions are univariate, except for a few instances where we need to control for some additional characteristics.

Columns (1) to (3) report the results on three measures of overconfidence: overplacement of performance, overplacement of literacy, and miscalibration of uncertainty. Out of these three measures of overconfidence, the only one that is significantly and positively related to turnover is overplacement of performance: in column (1), conditional on having the same past performance, investors who self-report having higher performance tend to trade more subsequently. In column (3), miscalibration of uncertainty does not significantly predict future turnover. These results are consistent with Glaser and Weber (2007), who also show overplacement predicts excess trading while miscalibration of uncertainty does not.

\footnotetext{
${ }^{24}$ If we measure turnover at the time of or before the survey, then the exercise is subject to the concern that some common shocks may have affected both survey responses and trading behavior. For instance, a positive shock to one's recent return may lead one to report a higher self-assessed performance-resulting in more overplacement of performance - and to trade more.
} 
Column (1) also shows that past performance positively predicts future turnover. In column (2), financial literacy positively predicts future turnover. This finding is in sharp contrast to a view that excessive trading may be driven by a lack of financial knowledge. Therefore, improving investors' financial literacy, a policy often advocated in emerging economies such as China, may not be effective in reducing excessive trading. Furthermore, column (2) shows that overplacement of literacy does not predict future turnover.

Columns (4) to (6) report the results on neglect of trading costs. Surprisingly, for all three measures we have constructed, none of them significantly predict future turnover with the predicted sign: in columns (4) and (5), the coefficients are close to zero and insignificant; in column (6), investors who do not understand the bid-ask spread as a form of trading cost trade less. The result in column (4) is particularly puzzling because the measure is constructed using direct estimates of transaction fees in a round-trip trade and should clearly identify those underestimating trading costs. ${ }^{25}$ That we cannot find any supporting evidence despite having constructed three measures for neglect of trading costs gives us pause about its role in explaining investor trading.

Columns (7) and (8) report the results on extrapolative beliefs. For the two measures of extrapolation of positive and negative returns, we do not find a strong relationship between extrapolative beliefs and turnover. One possibility is that extrapolation generates trading only in a bullish market (Barberis et al. 2018; Liao, Peng and Zhu 2020), but the period we examine is relatively quiet - the market increased by just a few percentage points during the 9-month window. Another possibility is that extrapolation alone cannot explain volume and must be combined with some additional forces to generate a trading frenzy (Liao, Peng and Zhu 2020).

Columns (9) and (10) report the results on gambling preference. We find that, consistent with the implications of Barberis and Huang (2008) and Bordalo, Gennaioli and Shleifer (2012), investors who are subject to gambling preference trade significantly more. Again, the question about "blockbusters" is much more powerful than the "lotteries" question. This is consistent with the pattern in Table 9, which shows gambling behavior can be explained by answers to the "blockbusters" question but not by answers to the "lotteries" question.

\footnotetext{
${ }^{25}$ Transaction fees are standard and almost homogeneous across different brokers. While some variation across brokers still remains, in our construction we use a rather conservative bound to identify those who underestimate trading costs. In addition, we control for differences in fees across brokers with branch fixed effect.
} 
Columns (11) and (12) report the results on realization utility and show an asymmetry. The first measure - the one that proxies for taking pleasure in selling winners-positively predicts future turnover, whereas the second measure - the one that proxies for feeling pain when selling losers-does not predict future turnover. This pattern is consistent with the implications of realization utility (Barberis and Xiong 2012), as investors who exhibit realization utility are more willing to let go of stocks in gains and to hold on to stocks in losses.

Columns (13) and (14) report the results on sensation seeking. Both the "novelty-seeking" and the "volatility-seeking" measures positively predict future turnover with a large coefficient. These results are consistent with the finding in Grinblatt and Keloharju (2009) and Dorn and Sengmueller (2009) that investors most prone to sensation seeking trade more frequently.

Columns (15) and (16) report the results on perceived information advantage and dismissiveness of others' information. Column (15) shows that those who believe in themselves having an information advantage trade more, whereas column (16) shows that those who are more dismissive do not trade more. As we discussed earlier, the first measure can capture a particular form of overconfidence if we can show these investors do not deliver better returns; indeed, we show this later Section 2.7. The second measure captures the dismissiveness modelled by Eyster, Rabin and Vayanos (2019). Thus, we find supportive evidence for perceived information advantage in explaining excessive trading, but not for dismissiveness.

Finally, columns (17) and (18) concern two measures of social influence. Interestingly, investors who are more influenced by their family, friends, and investment advisors tend to trade less, not more. This pattern does not lend support to the aforementioned literature that argues that social interaction contributes to the spread of investor sentiment and excessive trading. ${ }^{26}$ Columns (19) and (20) show that rational trading motives such as portfolio rebalancing needs and liquidity needs can only explain a small part of the variation in turnover across investors.

In sum, Table 10 confirms several of the existing explanations for trading volume: for example, overplacement of performance, gambling preference, sensation seeking, realization utility, and perceived information advantage. Table 10 also shows a number of "null" results for some

\footnotetext{
${ }^{26}$ However, we note that recent models of social interactions such as Han, Hirshleifer and Walden (2020) are inherently conditional: social interactions lead to more trading when the market is going up and people are making money. Our tests rely on a period of quiet market reactions and therefore does not test these models directly.
} 
prominent explanations of excessive trading: for example, lack of financial literacy, neglect of trading costs, dismissiveness, and social interaction.

\subsection{Horse Race Results on Turnover}

Although the baseline results confirm several of the previous explanations for trading volume, it remains unclear whether their explanatory power will survive once they are all included in the same regression. Such a horse race has not been run before. Table 11 presents the full regression results. In addition to including all the survey-based trading motives, we also include: 1) basic demographic characteristics such as gender, income, net worth, and education; 2) return expectations to control for differences in optimism and pessimism; and 3) recent performance to control for "mood." 27 Table 11 reveals a number of notable observations.

First, two trading motives stand out in the horse race: gambling preference ("blockbusters") and overconfidence in the form of perceived information advantage. Both coefficients are quantitatively large and significant at the $1 \%$ level. The finding of overconfidence as a key driver of turnover supports the large volume of prior studies emphasizing the roles of overconfidence. Even more interesting, our finding highlights that a particular form of overconfidence through perceived information advantage - rather than other forms such as overplacement of literacy and miscalibration of uncertainty - is most relevant in explaining trading. This form of overconfidence also confirms the specification adopted by Kyle and Wang (1997), Daniel, Hirshleifer and Subrahmanyam (1998, 2001), Odean (1998), Gervais and Odean (2001), and Scheinkman and Xiong (2003) in modeling investor overconfidence in financial markets.

Our finding of gambling preference as a key driver of investor trading is surprising. Earlier literature tends to treat gambling preference as an important mechanism for understanding demand for lottery-like stocks but hasn't fully established its link with excessive trading. Our finding suggests that gambling preference may also lead investors to trade more. Barber and Odean (2000) conjecture a mechanism that works as follows. As individual stocks fluctuate in their volatility and tail distribution, the set of lottery-like stocks changes over time. Consequently, investors subject to gambling preference chase one lottery-like stock after another, leading to large trading volume.

\footnotetext{
${ }^{27}$ We also have a specification that includes branch fixed effects to control for clustering at the branch level. Results are essentially unchanged and reported in Table A8 of the Online Appendix.
} 
We note several interesting aspects of our findings of perceived information advantage and gambling preference as the most powerful factors in explaining turnover. First, note that in Table 8 , perceived information advantage is supported by only $18 \%$ of the respondents and gambling preference (for blockbusters) by $37 \%$. Both are substantially lower than some other factors with over $60 \%$ supporting rates. Therefore, although the two motives affect a small fraction of the population, their explanatory power is greater. This contrast also echoes our earlier discussion that question-specific biases may make it challenging to rely on the simple ranking of survey responses to compare the importance of different trading motives in explaining actual turnover.

Second, in Table 8, the correlation coefficient between perceived information advantage and gambling preference for blockbusters is -0.06 . The small correlation suggests that overconfidence and gambling preference contribute to trading volume through two orthogonal channels. Below, we present additional evidence to support these trading motives as key drivers of excessive trading.

Third, several trading motives that are significant in the baseline regressions become insignificant or marginally significant in the horse race. They include financial literacy, sensation seeking for novelty, sensation seeking for volatility, social influence, and advisor influence. The results for the two sensation seeking measures are particularly striking: while both measures are highly significant in univariate regressions, their significance largely disappears after controlling for other factors, suggesting that their explanatory power is subsumed by other factors. The contrast between sensation seeking and gambling preference is also worth noting, given the literature sometimes mixes the two. Sensation seeking suggests that investors like to gamble because they derive utility from gambling activities independent of the final payoffs while gambling preference suggests that the appeal of gambles is ultimately driven by the potential of a large payoff. Our analysis suggests that, while sensation seeking and gambling preference are correlated, gambling preference is the more relevant factor for the observed trading.

Finally, consistent with the finding of Barber and Odean (2001), we report a significant gender effect: on average, the monthly turnover of male investors is $21 \%$ higher than female investors. Barber and Odean (2001) attribute this difference to overconfidence: men trade more because they are more overconfident. Interestingly, the gender effect in Table 11 persists even after controlling for various forms of overconfidence, suggesting the gender effect may go beyond overconfidence.

\subsection{Robustness and Subsample Analysis}


As robustness checks, we report the results from alternative regressions in Section 9 of the Online Appendix, including specifications in which we bootstrap standard errors, add branch fixed effects as control variables, use a larger sample that includes investors that have not traded for more than two years before the survey, and use a small sample that only includes investors who are active around the time of the survey. We also consider alternative measures of turnover, including: an equal-weighted version as opposed to the value-weighted one we use throughout the paper; and a version measured in the nine-month window before the survey, as opposed to the nine-month window after the survey. Throughout all these specifications, gambling preference and perceived information advantage remain the most powerful factors for explaining turnover.

We also perform two sets of subsample analysis and report the results in Section 9 of the Online Appendix. In the first one, we split the full sample based on account size and compare the behaviors of small and large investors. Overall, consistent with the notion that small investors are more affected by behavioral biases, we find that the results are slightly stronger among small investors. In the second subsample, we split the full sample based on the fraction of wealth invested in the stock market. In both subsamples, gambling preference and perceived information advantage remain significant factors. However, for investors whose wealth is more invested in the stock market, portfolio rebalancing needs become a more pronounced factor to their trading.

We discuss two limitations of our horse race. First, it is possible that the importance of each mechanism is time-varying. Without a panel of survey responses, we can only capture a snapshot of their relative importance. For instance, realization utility (Barberis and Xiong 2012; Liao, Peng and Zhu 2020) and social interactions (Han, Hirshleifer and Walden 2020) may contribute to excessive trading more in a market boom than in a market downturn. However, we show, in Table A17 of the Online Appendix, that the explanatory power of each motive remains stable during the 9-month window before the survey, suggesting relatively persistent importance in the time series. Second, and relatedly, it is also possible that some retail investors learn to debias themselves from past mistakes, and the importance of certain mechanisms may decay over time (Seru, Shumway and Stoffman 2010). While our cross-sectional setting does not allow us to directly speak to the issue of learning, we note that some recent evidence suggests that retail investors do not appear to learn from their prior mistakes (e.g., Anagol, Balasubramaniam and Ramadorai 2019).

\subsection{Additional Evidence of Excessive Trading}


Trading is not necessarily excessive if more trading is associated with better returns. We further examine the portfolio returns based on investors' responses to the gambling preference and perceived information advantage questions to show that indeed the associated trading is excessive.

Panel A of Table 12 sorts investors into five groups based on their answers to the "blockbusters" question and reports each group's monthly turnover and portfolio return. While this single-sorting approach ignores the correlations of gambling preference with other trading motives, it provides a more granular look at the explanatory power of gambling preference. ${ }^{28}$ For turnover, there is a monotonically increasing pattern from the least gambling-prone to the most gambling-prone group. This monotonic pattern is present not just in the mean and the median of the monthly turnover rate, but also across various percentiles in the distribution, indicating that this pattern is not driven by outliers. On average, the difference between the "strongly agree" group and the "strongly disagree" group is about $21 \%$, suggesting sizable economic significance-a monthly turnover rate of $21 \%$ translates into an annualized transaction fee of $0.6 \%$.

Is the trading associated with gambling preference excessive? The result shows that this is the case: the five groups exhibit similar raw returns before fees. In fact, the "strongly agree" group on average earns $-0.35 \%$ lower monthly returns than the "strongly disagree" group, albeit the difference is not statistically significant. Together, the lack of superior performance and the large transaction costs suggest their trading is excessive.

We also examine the characteristics of stocks purchased by the five groups of investors in Table A18 of the Online Appendix. Investors with a survey-based gambling preference tend to buy stocks that are smaller, have a larger market beta, and have larger counts of daily up-limit hits, and higher past volatility and past returns. These stocks also perform worse subsequently, confirming that investors with a gambling preference trade in the wrong direction and their trading is excessive.

Panel B of Table 12 performs a similar exercise by sorting investors into five groups based on their answers to the "information advantage". Similar to before, investors who "always" think they have an information advantage exhibit higher turnover than those who "never" think so for almost all the distribution percentiles we look at. The magnitude is also similar: the difference in the

\footnotetext{
${ }^{28}$ Note that the coefficient of gambling preference is virtually unchanged from the univariate regression to the horse race, suggesting that the effect is not affected by other trading motives.
} 
monthly turnover rate between the "always" and the "never" groups is about $24 \%$, implying an annual transaction fee of $0.7 \%$.

Is the perceived information advantage supported by superior performance in portfolio returns? This is not the case: the five groups exhibit similar performance before fees, indicating that those who report having an information advantage do not outperform others in selecting better stocks. Accounting for trading fees would make their net performance clearly worse. Thus, the perceived information advantage reflects a form of overconfidence rather than genuinely better information.

\subsection{Neglect of Trading Costs}

In both the baseline and the horse race, none of the survey variables for neglect of trading costs can explain turnover in the right direction. This contradicts the popular view that Chinese retail investors trade so much because they neglect trading costs. In Table 10 and Table 11, some measures even suggest an opposite pattern that investors with more awareness of trading costs trade more. This pattern, however, may reflect a reverse selection that investors who trade more incur more total costs and are more aware of their existence. To further isolate the effect of awareness of trading costs, we have also implemented a randomized experiment.

Among all the 500 brokerage branches we distributed the survey to, we randomly selected 250 branches to include an additional "nudge." The "nudge" asked the respondent to read a onepage article that highlighted the negative consequences of excessive trading. As shown in Figure A3 in the Online Appendix, the article contained a detailed calculation of how much investors lose from frequent trading along with a quote from Warren Buffett advising investors to buy and hold. Instead of presenting trading costs as a fraction of total transaction value, we made it more salient by presenting the annualized fee rate for a frequent trader. We also included a "validation" question after the article by asking the respondent to compute the total trading cost for a given level of turnover. Answers to this question help identify those who have actually read the article and therefore were treated. We study the effect of this "nudge" in a difference-in-difference framework and report the results in Table A19 of the Online Appendix. Overall, the nudge had no effect on reducing trading. One might argue that the "nudge" was not sufficiently strong, and the treated group may not have read the article carefully. However, we identify an investor as treated only if they were in the treated group and answered the "validation" question correctly. 
Taken together, our analysis suggests that neglect of trading costs is not a key driver of excessive trading. This finding has an important policy implication. Policy makers across the world, including China's stock market regulator, the China Securities Regulatory Commission (CSRC), frequently use Tobin taxes as a policy tool to curb speculative trading in stock markets. To the extent that investors may engage in excessive trading despite their awareness of the trading costs, our finding casts doubt on the effectiveness of Tobin taxes. ${ }^{29}$

\section{Comparing Survey-Based and Transaction-Based Measures}

In our analysis so far, we have taken survey responses as direct measures of trading motives and use them to study why investors trade so much. These survey-based measures have some clear advantages over transaction-based measures. First, well-designed survey questions can measure trading motives in a way closer to textbook definitions. Second, survey responses allow researchers to measure a large set of trading motives from the perspectives of the respondents at the same time, including those that are hard to measure from administrative data. However, there are also various concerns about survey data. The primary concern, the one we have already addressed through various validation exercises, is that survey responses may not capture actual trading behavior. A second concern is that survey responses are noisy: perhaps respondents, on average, do answer truthfully, but their responses at the individual level may be noisy. This is a concern that also arises in our setting. For instance, in Table 9, while the relationship between survey-based gambling preference and transaction-based gambling behavior is statistically significant, the $R$-squared is rather small across all specifications.

This concern about noise in survey responses raises a follow-up question: do transaction-based behavioral measures have stronger power than survey-based measures? We address this question by comparing survey-based and transaction-based measures of gambling behavior. Table 13 reports the results when we sort investors into different groups based on their gambling behavior directly measured from transaction data in the pre-survey sample period. This transaction-based measure turns out to be much more powerful in explaining turnover in the post-survey sample: the difference in the monthly turnover rate between the top and bottom groups is $97 \%$, quadrupling

\footnotetext{
${ }^{29}$ There is mixed evidence on the effects of Tobin taxes in reducing speculative trading and price volatility. See Song and Xiong (2018) for a detailed review of the CSRC's policy interventions in the stock market and Deng, Liu and Wei (2018) and Cai et al. (2019) for studies of effects of increasing the stamp tax for stock trading in China.
} 
the magnitude of $21 \%$ reported in Table 12 based on the survey-based measure of gambling behavior.

If this transaction-based measure of gambling behavior is so powerful, why don't we use it directly instead of relying on the survey-based measure? To address this question, we regress the transaction-based measure of gambling behavior on all survey-based trading motives and report the results in Table 14. It is reassuring to see that the survey-based measure of gambling preference is indeed the most powerful explanatory variable in this regression. However, a number of other survey-based trading motives are also significantly correlated with the transaction-based measure of gambling behavior. For instance, investors with perceived information advantage also gamble more. Therefore, although the transaction-based measure of gambling behavior is more powerful in explaining trading, this measure is partially correlated with other trading motives and its explanatory power may not come solely from gambling preference. ${ }^{30}$

Taken together, our results show a trade-off between survey-based and transaction-based measures of trading motives. Survey-based measures have stronger power from the economic perspective of qualitatively testing different trading motives, even though they may contain more noise and thus have weaker statistical power. Transaction-based measures have stronger statistical power, but one measure may reflect multiple mechanisms and the economic interpretations are thus not as sharp as survey-based measures.

\section{Conclusion}

We propose a new approach to consolidate the zoo of behavioral biases by examining the cross-sectional explanatory power of survey-based measures of different biases for certain observed investor behavior. This approach allows researchers to examine multiple mechanisms at the same time and addresses some econometric issues that arise in a purely survey-based approach. We illustrate this approach by designing and administering a nationwide survey to study why investors trade so much. We highlight a number of new findings. First, survey responses are consistent with actual trading behaviors. Second, overconfidence (in having an information

\footnotetext{
${ }^{30}$ The transaction-based measure of gambling behavior may also contain effects from other omitted variables. For example, one possible omitted variable is investor attention-investors who pay more attention to the stock market are more likely to be drawn to lottery-like stocks as they appear more often in the news. While these investors may exhibit gambling-like behavior, their frequent trading is explained by their attention to the stock market.
} 
advantage) and gambling preference dominate other trading motives in explaining observed turnover, despite their relatively low supporting rates in the survey. Third, popular arguments such as neglect of trading costs and low financial literacy do not contribute to excessive trading. Finally, by analyzing the pros and cons of survey-based and transaction-based approaches, we argue that our integrated approach can help mitigate the concerns faced by each of these approaches alone.

The analysis in this paper has focused on one of the fundamental puzzles in financial markets: why do retail investors trade so much? A similar exercise can be carried out to compare competing mechanisms for other anomalies. It is possible that a few mechanisms are most relevant for explaining multiple anomalies, but it is also possible that different mechanisms are driving different anomalies. In this regard, our exercise takes a necessary first step to eventually tame the bias zoo.

\section{References}

Allen, Franklin, Jun "QJ" Qian, Chenyu Shan, and Julie Lei Zhu, 2020, The Development of the Chinese Stock Market, in Marlene Amstad, Guofeng Sun, Wei Xiong ed.: Handbook of China's Financial System (Princeton University Press).

Alpert, M., \& Raiffa, H. (1982). A Progress Report on the Training of Probability Assessors.

Anagol, Santosh, Vimal Balasubramaniam, and Tarun Ramadorai, 2020, Learning from Noise: Evidence from India's IPO lotteries, Journal of Financial Economics, forthcoming.

Barber, Brad M., Xing Huang, Kwangmin Ko, and Terrance Odean, 2020, Leveraging Overconfidence, Working paper.

Barber, Brad M., Yi-Tsung Lee, Yu-Jane Liu, and Terrance Odean, 2009, Just How Much Do Individual Investors Lose by Trading? Review of Financial Studies 22, 609-632.

Barber, Brad M., and Terrance Odean, 2000, Trading Is Hazardous to Your Wealth: The Common Stock Investment Performance of Individual Investors, Journal of Finance 55, 773-806.

Barber, Brad M., and Terrance Odean, 2001, Boys will be Boys: Gender, Overconfidence, and Common Stock Investment, Quarterly Journal of Economics 116, 261-292.

Barber, Brad M., and Terrance Odean, 2013, The Behavior of Individual Investors, in George Constantinides ed.: Handbook of the Economics of Finance (Elsevier).

Barberis, Nicholas, 2018, Psychology-Based Models of Asset Prices and Trading Volume, Handbook of Behavioral Economics: Applications and Foundations 1 (North-Holland).

Barberis, Nicholas, Robin Greenwood, Lawrence Jin, and Andrei Shleifer, 2015, X-CAPM: An Extrapolative Capital Asset Pricing Model, Journal of Financial Economics 115, 1-24.

Barberis, Nicholas, Robin Greenwood, Lawrence Jin, and Andrei Shleifer, 2018, Extrapolation and Bubbles, Journal of Financial Economics 129, 203-227. 
Barberis, Nicholas, Lawrence Jin, and Baolian Wang, 2020, Prospect Theory and Stock Market Anomalies, Working paper.

Barberis, Nicholas, and Ming Huang, 2008, Stocks as Lotteries: The Implications of Probability Weighting for Security Prices, American Economic Review 98, 2066-2100.

Barberis, Nicholas, Andrei Shleifer, and Robert Vishny, 1998, A Model of Investor Sentiment, Journal of Financial Economics 49, 307-343.

Barberis, Nicholas, and Wei Xiong, 2009, What Drives the Disposition Effect? An Analysis of a Long-Standing Preference-Based Explanation, Journal of Finance 64, 751-784.

Barberis, Nicholas, and Wei Xiong, 2012, Realization Utility, Journal of Financial Economics 104, 251-271.

Ben-David, Itzhak, John R. Graham, and Campbell R. Harvey, 2013, Managerial Miscalibration, Quarterly Journal of Economics 128, 1547-1584.

Benos, Alexandros V., 1998, Aggressiveness and Survival of Overconfident Traders, Journal of Financial Markets 1, 353-383.

Bertrand, Marianne, and Sendhil Mullainathan, 2001, Do People Mean What They Say? Implications for Subjective Survey Data, American Economic Review 91, 67-72.

Birru, Justin, 2015, Confusion of Confusions: A Test of the Disposition Effect and Momentum, Review of Financial Studies 28, 1849-1873.

Bordalo, Pedro, Nicola Gennaioli, and Andrei Shleifer, 2012, Salience Theory of Choice Under Risk, Quarterly Journal of Economics 127, 1243-1285.

Boyer, Brian, Todd Mitton, and Keith Vorkink, 2010, Expected Idiosyncratic Skewness, Review of Financial Studies 23, 169-202.

Brown, Stephen, Yan Lu, Sugata Ray, and Melvyn Teo, 2018, Sensation Seeking and Hedge Funds, Journal of Finance 73, 2871-2914.

Cai, Jinghan, Jibao He, Wenxi Jiang, and Wei Xiong, 2019, The Whack-A-Mole Game: Tobin Taxes and Trading Frenzy, Review of Financial Studies, forthcoming.

Chetty, Raj, Adam Looney, and Kory Kroft, 2009, Salience and Taxation: Theory and Evidence, American Economic Review 99, 1145-1177.

Chinco, Alex, Samuel M. Hartzmark, and Abigail B. Sussman, 2020, Risk-Factor Irrelevance, Working paper.

Choi, James J., and Adriana Z. Robertson, 2020, What Matters to Individual Investors? Evidence from the Horse's Mouth, Journal of Finance 75, 1965-2020.

Da, Zhi, Xing Huang, and Lawrence J. Jin, 2020, Extrapolative Beliefs in the Cross-Section: What Can We Learn from the Crowds? Journal of Financial Economics, forthcoming.

Daniel, Kent, David Hirshleifer, and Avanidhar Subrahmanyam, 1998, Investor Psychology and Security Market Under- and Overreactions, Journal of Finance 53, 1839-1885.

Daniel, Kent, David Hirshleifer, and Avanidhar Subrahmanyam, 2001, Overconfidence, Arbitrage, and Equilibrium Asset Pricing, Journal of Finance 56, 921-965. 
DellaVigna, Stefano, and Elizabeth Linos, 2020, RCTs to Scale: Comprehensive Evidence from Two Nudge Units, Working paper.

Deng, Yongheng, Xin Liu, and Shang-Jin Wei, 2018, One Fundamental and Two Taxes: When Does a Tobin Tax Reduce Financial Price Volatility? Journal of Financial Economics 130, 663692.

Dorn, Daniel, and Gur Huberman, 2005, Talk and Action: What Individual Investors Say and What They Do, Review of Finance 9, 437-481.

Dorn, Daniel, and Paul Sengmueller, 2009, Trading as Entertainment? Management Science 55, 591-603.

Epper, Thomas, Ernst Fehr, Helga Fehr-Duda, Claus Thustrup Kreiner, David Dreyer Lassen, Søren Leth-Petersen, and Gregers Nytoft Rasmussen, 2020, Time Discounting and Wealth Inequality, American Economic Review 110, 1177-1205.

Eyster, Erik, Matthew Rabin, and Dimitri Vayanos, 2019, Financial Markets Where Traders Neglect the Informational Content of Prices, Journal of Finance 74, 371-399.

Fama, Eugene F., 1998, Market Efficiency, Long-Term Returns, and Behavioral Finance, Journal of Financial Economics 49, 283-306.

Friedman, Milton, 1953, The Methodology of Positive Economics, Essays in Positive Economics $3,145-178$.

Frydman, Cary, Nicholas Barberis, Colin Camerer, Peter Bossaerts, and Antonio Rangel, 2014, Using Neural Data to Test a Theory of Investor Behavior: An Application to Realization Utility, Journal of Finance 69, 907-946.

Frydman, Cary, and Antonio Rangel, 2014, Debiasing the Disposition Effect by Reducing the Saliency of Information about a Stock's Purchase Price, Journal of Economic Behavior and Organization 107, 541-552.

Frydman, Cary, and Baolian Wang, 2020, The Impact of Salience on Investor Behavior: Evidence from a Natural Experiment, Journal of Finance 75, 229-276.

Gao, Xiaohui, and Tse-Chun Lin, 2014, Do Individual Investors Treat Trading as a Fun and Exciting Gambling Activity? Evidence from Repeated Natural Experiments, Review of Financial Studies 28, 2128-2166.

Gervais, Simon, and Terrance Odean, 2001, Learning to Be Overconfident, Review of Financial Studies 14, 1-27.

Giglio, Stefano, Matteo Maggiori, Johannes Stroebel, and Steve Utkus, 2020, Five Facts about Beliefs and Portfolios, American Economic Review, forthcoming.

Glaser, Markus, and Martin Weber, 2007, Overconfidence and Trading Volume, Geneva Risk and Insurance Review 32, 1-36.

Graham, John R, Campbell R Harvey, and Hai Huang, 2009, Investor Competence, Trading Frequency, and Home Bias, Management Science 55, 1094-1106.

Grampp, William D, 1948, Adam Smith and the Economic Man, Journal of Political Economy 56, No. 4: 315-336. 
Greenwood, Robin, and Andrei Shleifer, 2014, Expectations of Returns and Expected Returns, Review of Financial Studies 27, 714-746.

Grinblatt, Mark, and Bing Han, 2005, Prospect Theory, Mental Accounting, and Momentum, Journal of Financial Economics 78, 311-339.

Grinblatt, Mark, and Matti Keloharju, 2001, How Distance, Language, and Culture Influence Stockholdings and Trades, Journal of Finance 56, 1053-1073.

Grinblatt, Mark, and Matti Keloharju, 2009, Sensation Seeking, Overconfidence, and Trading Activity, Journal of Finance LXIV, 549-578.

Grinblatt, Mark, Matti Keloharju, and Juhani Linnainmaa, 2011, IQ and Stock Market Participation, Journal of Finance 66, 2121-2164.

Grossman, Sanford J., and Joseph E. Stiglitz, 1980, On the Impossibility of Informationally Efficient Markets, American Economic Review 70, 393-408.

Han, Bing, David Hirshleifer, and Johan Walden, 2020, Social Transmission Bias and Investor Behavior, Working paper.

Hirshleifer, David, 2015, Behavioral Finance, Annual Review of Financial Economics, 7, 133-159.

Hong, Harrison, Jeffrey D Kubik, and Jeremy C Stein, 2004, Social Interaction and Stock-Market Participation, Journal of Finance 59, 137-163.

Hong, Harrison, José Scheinkman, and Wei Xiong, 2008, Advisors and Asset Prices: A Model of the Origins of Bubbles, Journal of Financial Economics 89, 268-287.

Hong, Harrison, and Jeremy C. Stein, 1999, A Unified Theory of Underreaction, Momentum Trading, and Overreaction in Asset Markets, Journal of Finance 54, 2143-2184.

Ingersoll, Jr., Jonathan E., and Lawrence J. Jin, 2013, Realization Utility with ReferenceDependent Preferences, Review of Financial Studies 26, 723-767.

Jin, Lawrence J., and Pengfei Sui, 2019, Asset Pricing with Return Extrapolation, Working paper.

Kahneman, Daniel, and Shane Frederick, 2002, Representativeness Revisited: Attribute Substitution in Intuitive Judgment, Heuristics and Biases: The Psychology of Intuitive Judgment 49: 81 .

Kelly, Morgan, and Cormac O Grada, 2000, Market Contagion: Evidence from the Panics of 1854 and 1857, American Economic Review 90, 1110-1124.

Koijen, Ralph, Stijn Van Nieuwerburgh, and Roine Vestman, 2015, Judging the Quality of Survey Data by Comparison with "Truth" as Measured by Administrative Records Evidence from Sweden, in Improving the Measurement of Consumer Expenditures, pp. 308-346, University of Chicago Press.

Kreiner, Claus Thustrup, David Dreyer Lassen, and Søren Leth-Petersen, 2015, Measuring the Accuracy of Survey Responses Using Administrative Register Data: Evidence from Denmark, in Improving the Measurement of Household Consumption Expenditures, pp. 289-307, University of Chicago Press.

Kumar, Alok, 2009, Who Gambles in the Stock Market? Journal of Finance 64, 1889-1933.

Kyle, Albert S., 1985, Continuous Auctions and Insider Trading, Econometrica 53, 1315-1335. 
Kyle, Albert S., and F. Albert Wang, 1997, Speculation Duopoly with Agreement to Disagree: Can Overconfidence Survive the Market Test? Journal of Finance 52, 2073-2090.

Liao, Jingchi, Cameron Peng, and Ning Zhu, 2020, Price and Volume Dynamics in Bubbles, Working paper.

Lusardi, Annamaria, and Olivia S. Mitchell, 2007, Baby Boomer Retirement Security: The Roles of Planning, Financial Literacy, and Housing Wealth, Journal of Monetary Economics 54, 205224.

Lusardi, Annamaria, and Olivia S. Mitchell, 2011, Financial Literacy around the World: An Overview, Journal of Pension Economics and Finance 10, 497-508.

Lusardi, Annamaria, and Olivia S. Mitchell, 2014, The Economic Importance of Financial Literacy: Theory and Evidence, Journal of Economic Literature 52, 5-44.

Milgrom, Paul, and Nancy Stokey, 1982, Information, Trade and Common Knowledge, Journal of Economic Theory 26, 17-27.

Odean, Terrance, 1998, Volume, Volatility, Price, and Profit When All Traders Are Above Average, Journal of Finance 53, 1887-1934.

Odean, Terrance, 1999, Do Investors Trade Too Much? American Economic Review 89, 12791298.

Pool, Veronika K., Noah Stoffman, and Scott E. Yonker, 2015, The People in Your Neighborhood: Social Interactions and Mutual Fund Portfolios, Journal of Finance 70, 2679-2732.

Scheinkman, José A., and Wei Xiong, 2003, Overconfidence and Speculative Bubbles, Journal of Political Economy 111, 1183-1219.

Seru, Amit, Tyler Shumway, and Noah Stoffman, 2010, Learning by Trading, Review of Financial Studies 23, 705-739.

Shefrin, Hersh, and Meir Statman, 1985, The Disposition to Sell Winners Too Early and Ride Losers Too Long: Theory and Evidence, Journal of Finance 40, 777-790.

Shefrin, Hersh, and Meir Statman, 2000, Behavioral Portfolio Theory, Journal of Financial and Quantitative Analysis 35, 127-151.

Shiller, Robert J., 1984, Stock Prices and Social Dynamics, Brookings Papers on Economic Activity 2, 457-510.

Shiller, Robert J., 1989, Comovements in Stock Prices and Comovements in Dividends, Journal of Finance 44, 719-729.

Song, Zheng (Michael), and Wei Xiong, 2018, Risks in China's Financial System, Annual Review of Financial Economics 10, 261-286.

Taubinsky, Dmitry, and Alex Rees-Jones, 2018, Attention Variation and Welfare: Theory and Evidence from a Tax Salience Experiment, Review of Economic Studies 85, 2462-2496.

Tversky, Amos, and Daniel Kahneman, 1992, Advances in Prospect Theory: Cumulative Representation of Uncertainty, Journal of Risk and Uncertainty 5, 297-323.

Van Rooij, Maarten, Annamaria Lusardi, and Rob Alessie, 2011, Financial Literacy and Stock Market Participation, Journal of Financial Economics 101, 449-472. 


\begin{tabular}{|c|c|c|}
\hline Theory & Forms of Representation & Papers \\
\hline Overconfidence & $\begin{array}{l}\text { 1. overplacement } \\
\text { 2. miscalibration of uncertainty }\end{array}$ & $\begin{array}{l}\text { Daniel, Hirshleifer and Subrahmanyam } \\
\text { (1998, 2001); Odean (1998); Benos (1998) } \\
\text { Glaser and Weber (2007); Dorn and } \\
\text { Huberman (2005); Graham, Harvey and } \\
\text { Huang (2009); Ben-David, Graham and } \\
\text { Harvey (2013) }\end{array}$ \\
\hline Extrapolation & $\begin{array}{l}\text { 1. upward trend to continue } \\
\text { 2. downward trend to continue }\end{array}$ & $\begin{array}{l}\text { Barberis et al. (2018); Jin and Sui (2019); } \\
\text { Da, Huang, and Jin (2020); Liao, Peng and } \\
\text { Zhu (2020) }\end{array}$ \\
\hline $\begin{array}{l}\text { Neglect } \\
\text { of trading costs }\end{array}$ & $\begin{array}{l}\text { 1. underestimation of transaction fees } \\
\text { 2. knowledge about the bid-ask spread } \\
\text { 3. salience of transaction fees }\end{array}$ & $\begin{array}{l}\text { Barber and Odean (2000); Barber et al. } \\
\text { (2009); Bordalo, Gennaioli and Shleifer } \\
\text { (2012) }\end{array}$ \\
\hline $\begin{array}{l}\text { Gambling } \\
\text { preferences }\end{array}$ & $\begin{array}{l}\text { 1. blockbuster } \\
\text { 2. lotteries }\end{array}$ & $\begin{array}{l}\text { Barber and Odean (2000); Shefrin and } \\
\text { Statman (2000); Barberis and Huang } \\
\text { (2008); Kumar (2009); Barber et al. } \\
\text { (2008); Bordalo, Gennaioli and Shleifer } \\
\text { (2012) }\end{array}$ \\
\hline $\begin{array}{l}\text { Realization } \\
\text { utility }\end{array}$ & $\begin{array}{l}\text { 1. utility from realizing gains } \\
\text { 2. disutility from realizing losses }\end{array}$ & $\begin{array}{l}\text { Barberis and Xiong }(2009,2012) \text {; Ingersoll } \\
\text { and Jin (2013); Frydman et al. (2014) }\end{array}$ \\
\hline $\begin{array}{l}\text { Sensation } \\
\text { seeking }\end{array}$ & $\begin{array}{l}\text { 1. novelty seeking } \\
\text { 2. volatility seeking }\end{array}$ & $\begin{array}{l}\text { Grinblatt and Keloharju (2009); Dorn and } \\
\text { Sengmueller (2009); Gao and Lin (2014) }\end{array}$ \\
\hline Information & $\begin{array}{l}\text { 1. perceived information advantage } \\
\text { 2. dismissiveness (of others' } \\
\text { information) }\end{array}$ & $\begin{array}{l}\text { Kyle and Wang (1997); Odean (1998); } \\
\text { Gervais and Odean (2001); Scheinkman } \\
\text { and Xiong (2003); Eyster, Rabin and } \\
\text { Vayanos (2019) }\end{array}$ \\
\hline $\begin{array}{l}\text { Social and advisor } \\
\text { influences }\end{array}$ & $\begin{array}{l}\text { 1. advisor influence } \\
\text { 2. social influence }\end{array}$ & $\begin{array}{l}\text { Shiller (1989); Kelly and Grada (2000); } \\
\text { Hong, Kubik and Stein (2004); Hong, } \\
\text { Scheinkman, and Xiong (2008); Pool, } \\
\text { Stoffman and Yonker (2015); Han, } \\
\text { Hirshleifer and Walden (2020) }\end{array}$ \\
\hline $\begin{array}{l}\text { Financial or } \\
\text { investment literacy }\end{array}$ & $\begin{array}{l}\text { 1. compounding } \\
\text { 2. inflation } \\
\text { 3. diversification } \\
\text { 4. asset risk } \\
\text { 5. definition of stocks } \\
\text { 6. definition of bonds } \\
\text { 7. the PE ratio } \\
\text { 8. definition of mutual funds }\end{array}$ & $\begin{array}{l}\text { Van Rooij, Lusardi and Alessie (2011); } \\
\text { Lusardi and Mitchell (2007, 2011, 2014); } \\
\text { Grinblatt, Keloharju and Linnainmaa } \\
\text { (2011) }\end{array}$ \\
\hline
\end{tabular}

Table 1: Summary of Theories on Trading Volume 


\begin{tabular}{|c|c|c|c|c|c|c|c|}
\hline Gender & Population & $\begin{array}{c}\text { All } \\
\text { Respondents }\end{array}$ & $\begin{array}{c}\text { Main } \\
\text { Sample }\end{array}$ & Income (RMB) & Population & $\begin{array}{c}\text { All } \\
\text { Respondents }\end{array}$ & $\begin{array}{c}\text { Main } \\
\text { Sample }\end{array}$ \\
\hline Male & $71.70 \%$ & $54.00 \%$ & $54.40 \%$ & $<20 \mathrm{~K}$ & NA & $3.80 \%$ & $2.08 \%$ \\
\hline \multirow[t]{2}{*}{ Female } & $28.30 \%$ & $46.00 \%$ & $45.60 \%$ & $20 \mathrm{~K}$ to $100 \mathrm{~K}$ & NA & $17.20 \%$ & $16.42 \%$ \\
\hline & & & & $100 \mathrm{~K}$ to $200 \mathrm{~K}$ & NA & $29.50 \%$ & $30.08 \%$ \\
\hline Education & & & & $200 \mathrm{~K}$ to $500 \mathrm{~K}$ & NA & $29.50 \%$ & $30.16 \%$ \\
\hline Middle school or blow & $7.30 \%$ & $8.60 \%$ & $8.10 \%$ & $500 \mathrm{~K}$ to $1 \mathrm{M}$ & NA & $12.60 \%$ & $13.74 \%$ \\
\hline High school & $24.70 \%$ & $15.60 \%$ & $18.35 \%$ & $1 \mathrm{M}$ to $2 \mathrm{M}$ & NA & $4.20 \%$ & $4.47 \%$ \\
\hline Professional school & $26.00 \%$ & $21.90 \%$ & $24.83 \%$ & $2 \mathrm{M}$ to $10 \mathrm{M}$ & NA & $2.10 \%$ & $2.46 \%$ \\
\hline College & $23.60 \%$ & $44.90 \%$ & $40.95 \%$ & $10 \mathrm{M}$ and above & NA & $1.20 \%$ & $0.58 \%$ \\
\hline Graduate school and above & $3.40 \%$ & $9.20 \%$ & $7.77 \%$ & & & & \\
\hline \multirow[t]{2}{*}{ Others } & $14.80 \%$ & $0.00 \%$ & $0.00 \%$ & Net worth (RMB) & & & \\
\hline & & & & $<20 \mathrm{~K}$ & NA & $4.80 \%$ & $2.57 \%$ \\
\hline Age & & & & $20 \mathrm{~K}$ to $100 \mathrm{~K}$ & NA & $12.30 \%$ & $9.59 \%$ \\
\hline$<30$ & $21.30 \%$ & $27.80 \%$ & $26.10 \%$ & $100 \mathrm{~K}$ to $500 \mathrm{~K}$ & NA & $27.50 \%$ & $25.50 \%$ \\
\hline 30 to 40 & $27.40 \%$ & $29.10 \%$ & $27.40 \%$ & $500 \mathrm{~K}$ to $1 \mathrm{M}$ & NA & $22.30 \%$ & $23.91 \%$ \\
\hline 40 to 50 & $24.50 \%$ & $19.90 \%$ & $22.40 \%$ & $1 \mathrm{M}$ to $2 \mathrm{M}$ & NA & $21.90 \%$ & $25.16 \%$ \\
\hline 50 to 60 & $15.10 \%$ & $14.80 \%$ & $16.00 \%$ & $2 \mathrm{M}$ to $10 \mathrm{M}$ & NA & $6.50 \%$ & $8.05 \%$ \\
\hline$>60$ & $11.70 \%$ & $8.50 \%$ & $8.10 \%$ & $10 \mathrm{M}$ and above & NA & $4.80 \%$ & $5.22 \%$ \\
\hline Investment age (in years) & & & & Trading characteristics in 2017 & & & \\
\hline$<2$ & $10.00 \%$ & NA & $21.20 \%$ & Maximum value of investment & 639 & NA & 1,250 \\
\hline 2 to 6 & $29.80 \%$ & NA & $26.20 \%$ & (in thousand RMB) & & & \\
\hline 6 to 10 & $18.00 \%$ & NA & $17.40 \%$ & Annual turnover rate & 9.4 & NA & 8.3 \\
\hline$>10$ & $42.20 \%$ & NA & $35.10 \%$ & Annual raw return rate & $-3.90 \%$ & NA & $-1.20 \%$ \\
\hline
\end{tabular}

Table 2 Summary Statistics for the Investor Population, Survey Respondents, and Investors in the Main Sample

Note: This table shows the summary statistics for the investor population, all respondents, and the main sample. The population's characteristics are obtained from the centralized database at the Shenzhen Stock Exchange. Survey respondents are the 12,856 investors who have completed the survey. The main sample includes 4,671 survey respondents that: 1) can be identified in the Shenzhen Stock Exchange centralized database, and 2) held at least one SZSE stock during the two-year window before the survey. Gender, education, and age are from either the SZSE centralized database or the survey answers. Investment age and trading characteristics in 2017 are calculated from trading records and thus missing for the survey respondents who cannot be identified in the SZSE centralized database. Income and net worth are obtained from the survey and thus missing for the investor population. See Table A2 in the Online Appendix for more details about variable definitions. 
Panel A: Correct Rate by Question

\begin{tabular}{|c|c|}
\hline Question & Correct rate \\
\hline $\begin{array}{l}\text { 1. Suppose you had } \$ 100 \text { in a savings account and the interest rate was } 2 \% \text { per } \\
\text { year. After } 5 \text { years, how much do you think you would have in the account if you } \\
\text { left the money to grow? }\end{array}$ & $88.4 \%$ \\
\hline $\begin{array}{l}\text { 2. Imagine that the interest rate on your savings account was } 1 \% \text { per year and } \\
\text { inflation was } 2 \% \text { per year. After } 1 \text { year, how much will you be able to buy with the } \\
\text { money in this account? }\end{array}$ & $91.5 \%$ \\
\hline $\begin{array}{l}\text { 3. Do you agree with the following statement? Buying an individual stock is } \\
\text { usually less risky than buying a stock mutual fund. }\end{array}$ & $86.2 \%$ \\
\hline 4. Normally, which asset displays the highest fluctuation over time? & $95.2 \%$ \\
\hline $\begin{array}{l}\text { 5. Which of the following statements is correct? If somebody buys a stock of firm } \\
\text { B in the stock market.... }\end{array}$ & $76.3 \%$ \\
\hline $\begin{array}{l}\text { 6. Normally, when the market interest rate falls, the price of an existing bond } \\
\text { will .... }\end{array}$ & $54.7 \%$ \\
\hline 7. What is the $\mathrm{P} / \mathrm{E}$ ratio? & $75.8 \%$ \\
\hline 8. Which of the following statements about mutual funds is correct? & $90.3 \%$ \\
\hline
\end{tabular}

Panel B: Distribution of Financial Literacy Scores

\begin{tabular}{|c|c|c|}
\hline Score & Actual & Self-assessed \\
\hline 0 & $0.4 \%$ & $0.6 \%$ \\
\hline 1 & $0.7 \%$ & $0.7 \%$ \\
\hline 2 & $1.7 \%$ & $1.8 \%$ \\
\hline 3 & $2.3 \%$ & $4.6 \%$ \\
\hline 4 & $5.1 \%$ & $6.9 \%$ \\
\hline 5 & $8.9 \%$ & $13.0 \%$ \\
\hline 6 & $17.9 \%$ & $16.2 \%$ \\
\hline 7 & $30.1 \%$ & $17.7 \%$ \\
\hline 8 & $33.0 \%$ & $32.7 \%$ \\
\hline $\mathrm{N} / \mathrm{A}$ & $0.0 \%$ & $5.8 \%$ \\
\hline
\end{tabular}

Table 3 Survey Responses on Questions on Financial Literacy

Note: This table shows the summary statistics of investors' responses to questions on financial literacy. In Panel A, we show the correct rate by question. In Panel B, we compare their actual and self-assessed performances, where actual performance is measured by the total number of questions answered correctly and self-assessed performance by the total number of questions one reports to have answered correctly. 


\begin{tabular}{|c|c|c|c|c|c|c|c|c|c|c|c|}
\hline \multicolumn{12}{|c|}{ Panel A: Overconfidence } \\
\hline 1. What fraction of retail & $<10 \%$ & $10-20 \%$ & $20-30 \%$ & $30-40 \%$ & $40-50 \%$ & $50-60 \%$ & $60-70 \%$ & $70-80 \%$ & $80-90 \%$ & $>90 \%$ & $\mathrm{~N} / \mathrm{A}$ \\
\hline $\begin{array}{l}\text { investors do you think earned } \\
\text { higher returns than you in } 2017 ?\end{array}$ & $11.8 \%$ & $13.8 \%$ & $15.8 \%$ & $13.5 \%$ & $12.4 \%$ & $10.4 \%$ & $5.8 \%$ & $3.8 \%$ & $2.2 \%$ & $3.4 \%$ & $7.2 \%$ \\
\hline 2. Actual score-Self-assessed & $<-4$ & -4 & -3 & -2 & -1 & 0 & 1 & 2 & 3 & 4 & $>4$ \\
\hline score & $0.8 \%$ & $1.8 \%$ & $5.4 \%$ & $11.4 \%$ & $19.7 \%$ & $35.1 \%$ & $17.7 \%$ & $5.6 \%$ & $1.7 \%$ & $0.6 \%$ & $0.4 \%$ \\
\hline 3. Upside return-Downside & $0 \%$ & $5 \%$ & $10 \%$ & $15 \%$ & $20 \%$ & $25 \%$ & $30 \%$ & $35 \%$ & $40 \%$ & $45 \%$ & $>50 \%$ \\
\hline return & $32.7 \%$ & $14.9 \%$ & $9.2 \%$ & $6.9 \%$ & $5.2 \%$ & $5.2 \%$ & $4.3 \%$ & $3.4 \%$ & $3.1 \%$ & $2.5 \%$ & $12.7 \%$ \\
\hline
\end{tabular}

\section{Panel B: Extrapolation}

1. After a stock's price keeps rising for a while, I usually believe that the price will rise even further in the future.

2. After a stock's price keeps falling for a while, I usually believe that the price will fall even further in the future.

$\begin{array}{cccccc}\text { Strongly } & & & & \text { Strongly } & \\ \text { Agree } & \text { Agree } & \text { Neutral } & \text { Disagree } & \text { Disagree } & \text { N/A } \\ 4.8 \% & 26.9 \% & 39.3 \% & 22.8 \% & 1.3 \% & 5.0 \% \\ \text { Strongly } & & & & \text { Strongly } & \\ \text { Agree } & \text { Agree } & \text { Neutral } & \text { Disagree } & \text { Disagree } & \text { N/A } \\ 4.4 \% & 29.1 \% & 41.9 \% & 18.2 \% & 1.3 \% & 5.3 \%\end{array}$

\section{Panel C: Neglect of Trading}

\section{Costs}

1. Estimating the cost of a round-trip buy and sell at the value of 10,000 RMB

\begin{tabular}{|c|c|c|c|c|c|c|c|}
\hline $0-5$ & $5-10$ & $10-15$ & $15-20$ & $20-25$ & $25-30$ & $30-35$ & $>35$ \\
\hline $17.3 \%$ & $27.7 \%$ & $23.6 \%$ & $12.8 \%$ & $8.4 \%$ & $3.7 \%$ & $2.1 \%$ & $5.5 \%$ \\
\hline Never & Rarely & Sometimes & Often & Always & N/A & & \\
\hline $14.6 \%$ & $37.7 \%$ & $27.0 \%$ & $13.8 \%$ & $4.6 \%$ & $2.5 \%$ & & \\
\hline & & Don't & Don't & & & & \\
\hline Agree & Disagree & Understand & Know & $\mathrm{N} / \mathrm{A}$ & & & \\
\hline $59.8 \%$ & $23.1 \%$ & $8.5 \%$ & $7.2 \%$ & $1.4 \%$ & & & \\
\hline
\end{tabular}

3. The bid-ask spread is one form of transaction cost (The bid-ask spread is the difference between the lowest ask price and the highest bid price).

Table 4 Summary Statistics for Responses to Questions, Part I

Note: This table tabulates the distribution of investors' answers to questions related to overconfidence (Q10, Q11, Q13, Q14), extrapolation (Q26, Q27), and neglect of trading costs (Q15, Q16, Q17). 


\section{Panel A: Gambling Preference}

\section{Blockbusters}

1. When I trade stocks, I aim to select those stocks whose price would rise sharply in a short period of time so that I can make a lot of money quickly.

Strongly Agree

$10.4 \%$

\section{Lotteries}

2. When I trade stocks, I often think of them as lotteries: I am willing to

accept small losses in exchange for the possibility of a big upside.
Strongly

Agree

$5.5 \%$
Agree

$25.4 \%$

Agree

Agree

$24.9 \%$

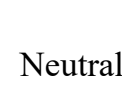

$33.9 \%$

Neutral

$27.2 \%$
Disagree

$23.0 \%$

Strongly

Disagree

$\mathrm{N} / \mathrm{A}$

$4.6 \%$

$2.7 \%$

Strongly

Disagree

$7.3 \%$

N/A

$2.7 \%$

\section{Panel B: Realization Utility}

\section{Winners}

1. Normally, if the price of a stock in your portfolio rose substantially since you bought it, which of these two actions would make you feel happier: holding on to the stock or selling that stock?

Sell

$37.2 \%$

2. Normally, if the price of a stock in your portfolio dropped substantially since you bought it, which of these two actions would make you feel more painful: holding on to the stock or selling that stock?

\section{Sell}

$22.9 \%$
Same

$23.7 \%$

Same

$28.0 \%$

Disagree

$32.5 \%$

(1.7\%

\section{Panel C: Sensation Seeking}

\section{$\underline{\text { Novelty }}$}

1. I feel excited about getting to know new stocks and new firms.

Strongly

Agree
$5.9 \%$

Agree
$20.3 \%$

Neutral

Neutral
$43.9 \%$

Hold

$25.3 \%$

No Feeling

$9.2 \%$

N/A

$5.9 \%$

Volatility

2. I feel excited about the stock market moving up and down.

Strongly

Agree

$5.4 \%$

Agree

$23.4 \%$

Hold

No Feeling

$12.2 \%$

$\mathrm{N} / \mathrm{A}$

$4.8 \%$

Table 5 Summary Statistics for Responses to Questions, Part II

Note: This table tabulates the distribution of investors' answers to questions related to gambling preference (Q18, Q19), realization utility (Q20, Q21), and sensation seeking (Q22, Q23). 


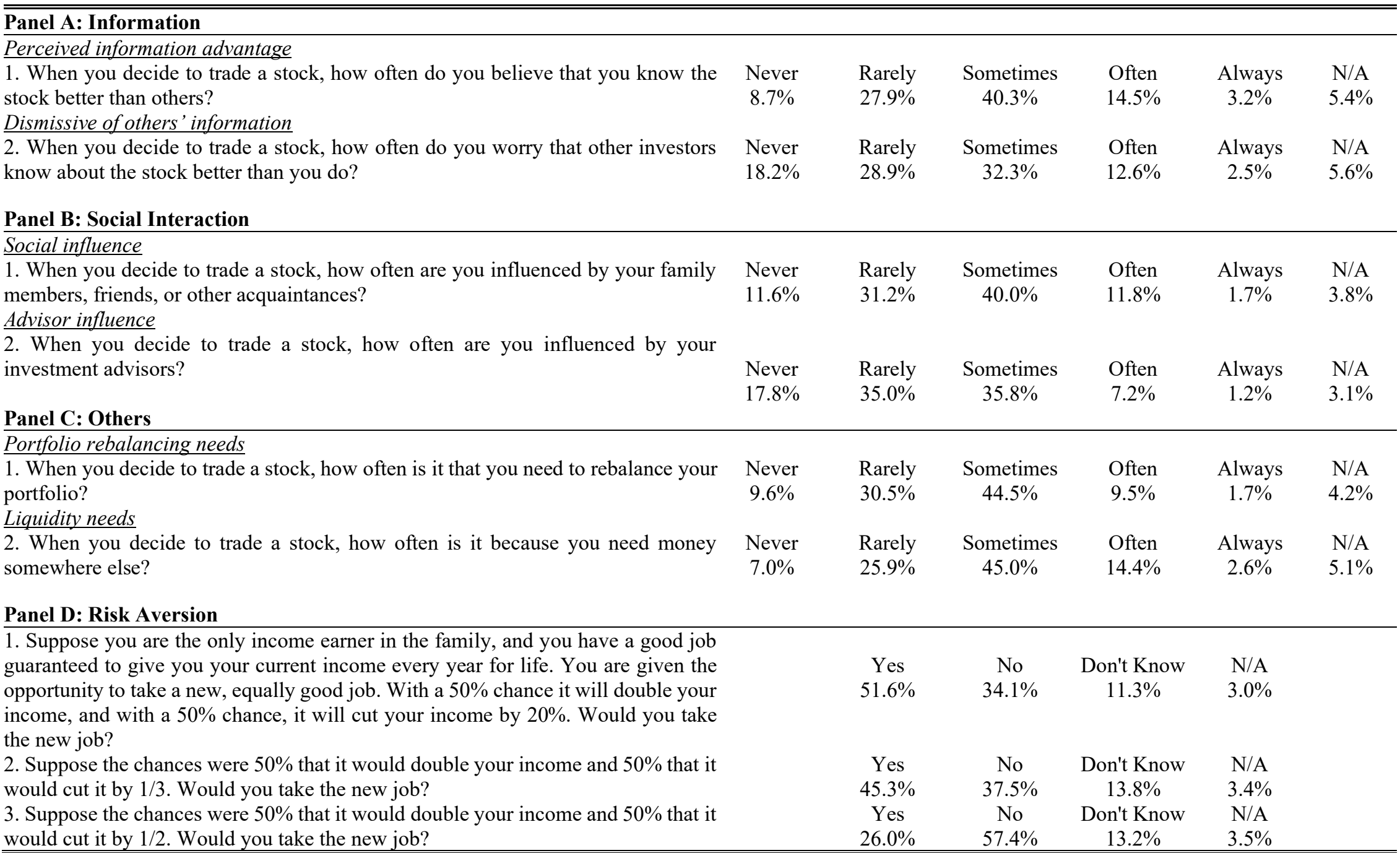

Table 6 Summary Statistics for Responses to Questions, Part III

Note: This table tabulates the distribution of investors' answers to questions related to information (Q24, Q25), social interaction (Q28, Q29), others (Q30, Q31), and risk aversion (Q32, Q33, Q34). 


\begin{tabular}{lccccccc}
\hline \hline \multicolumn{7}{c}{ Panel A: Summary Statistics } \\
\hline \multirow{3}{*}{ Turnover } & Min & P25 & Median & P75 & Max & Mean & Std Dev \\
Raw returns & $0.0 \%$ & $4.7 \%$ & $35.5 \%$ & $109.8 \%$ & $650.6 \%$ & $84.8 \%$ & $123.4 \%$ \\
Net returns & $-12.6 \%$ & $-1.4 \%$ & $0.0 \%$ & $2.0 \%$ & $10.0 \%$ & $0.0 \%$ & $3.5 \%$ \\
& $-12.9 \%$ & $-1.6 \%$ & $0.0 \%$ & $1.8 \%$ & $9.6 \%$ & $-0.2 \%$ & $3.6 \%$ \\
& \multicolumn{7}{c}{ Panel B: Correlation Matrix } \\
\hline
\end{tabular}

\begin{tabular}{|c|c|c|}
\hline & Turnover & Raw returns Net returns \\
\hline Turnover & 1 & \\
\hline Raw returns & $-0.07 * * *$ & 1 \\
\hline Net returns & $-0.16 * * *$ & $0.99 * * *$ \\
\hline
\end{tabular}

Table 7 Summary Statistics of Turnover and Portfolio Returns

Note: Panel A shows the summary statistics of the monthly turnover, raw return, and net return for investors in the main sample between October 2018 and June 2019. The main sample includes 4,671 survey respondents that: 1) can be identified in the Shenzhen Stock Exchange centralized database, and 2) held at least one SZSE stock during the two-year window before the survey. Panel B shows the correlation coefficients among the three variables. See Table A2 in the Online Appendix for more details about variable definitions. 


\begin{tabular}{|c|c|c|c|c|c|c|c|c|c|c|c|c|c|c|c|c|c|c|c|c|c|c|c|}
\hline & Variable & Mean & 1 & 2 & 3 & 4 & 5 & 6 & 7 & 8 & 9 & 10 & 11 & 12 & 13 & 14 & 15 & 16 & 17 & 18 & 19 & 20 & 21 \\
\hline 1 & Overplacement, performance & 0.67 & 1.00 & & & & & & & & & & & & & & & & & & & & \\
\hline 2 & Overplacement, literacy & 0.24 & 0.03 & 1.00 & & & & & & & & & & & & & & & & & & & \\
\hline 3 & Miscalibration & 0.69 & 0.08 & 0.02 & 1.00 & & & & & & & & & & & & & & & & & & \\
\hline 4 & Underestimation of transaction costs & 0.69 & -0.02 & 0.02 & 0.00 & 1.00 & & & & & & & & & & & & & & & & & \\
\hline 5 & Do not consider transaction costs & 0.53 & 0.03 & -0.01 & 0.01 & 0.11 & 1.00 & & & & & & & & & & & & & & & & \\
\hline 6 & Do not think bid-ask spread is a cost & 0.33 & -0.01 & -0.01 & -0.05 & -0.08 & -0.06 & 1.00 & & & & & & & & & & & & & & & \\
\hline 7 & Extrapolation, up & 0.32 & -0.01 & 0.04 & 0.02 & 0.00 & 0.08 & -0.09 & 1.00 & & & & & & & & & & & & & & \\
\hline 8 & Extrapolation, down & 0.34 & 0.00 & 0.04 & 0.02 & 0.00 & 0.07 & -0.10 & 0.62 & 1.00 & & & & & & & & & & & & & \\
\hline 9 & Gambling preference, blockbusters & 0.37 & -0.01 & 0.04 & -0.01 & -0.02 & 0.05 & -0.09 & 0.25 & 0.21 & 1.00 & & & & & & & & & & & & \\
\hline 10 & Gambling preference, lotteries & 0.30 & -0.01 & 0.04 & 0.01 & 0.02 & 0.07 & -0.10 & 0.24 & 0.21 & 0.40 & 1.00 & & & & & & & & & & & \\
\hline 11 & Realization utility, winners & 0.36 & -0.03 & 0.02 & 0.05 & 0.07 & 0.01 & -0.09 & -0.01 & 0.05 & 0.04 & 0.07 & 1.00 & & & & & & & & & & \\
\hline 12 & Realization utility, losers & 0.22 & 0.01 & 0.02 & -0.01 & 0.03 & 0.04 & -0.08 & 0.06 & 0.06 & 0.04 & 0.04 & 0.22 & 1.00 & & & & & & & & & \\
\hline 13 & Sensation seeking, novelty & 0.24 & -0.03 & 0.03 & 0.00 & 0.03 & 0.08 & -0.12 & 0.19 & 0.18 & 0.18 & 0.24 & 0.07 & 0.12 & 1.00 & & & & & & & & \\
\hline 14 & Sensation seeking, volatility & 0.29 & 0.00 & 0.04 & 0.03 & 0.03 & 0.05 & -0.12 & 0.22 & 0.23 & 0.22 & 0.26 & 0.09 & 0.13 & 0.42 & 1.00 & & & & & & & \\
\hline 15 & Perceived information advantage & 0.18 & 0.06 & 0.07 & 0.01 & -0.02 & -0.03 & -0.03 & -0.01 & 0.01 & -0.06 & -0.09 & -0.02 & -0.02 & 0.01 & 0.02 & 1.00 & & & & & & \\
\hline 16 & Dismissive of others' information & 0.14 & -0.02 & 0.03 & -0.03 & -0.05 & -0.11 & 0.08 & -0.03 & 0.01 & 0.02 & -0.01 & -0.01 & -0.04 & -0.02 & -0.03 & 0.14 & 1.00 & & & & & \\
\hline 17 & Social influence & 0.13 & -0.01 & 0.02 & -0.04 & -0.04 & -0.02 & 0.07 & -0.01 & -0.01 & 0.06 & 0.05 & 0.01 & -0.02 & 0.00 & -0.03 & 0.01 & 0.22 & 1.00 & & & & \\
\hline 18 & Advisor influence & 0.07 & -0.01 & 0.01 & -0.01 & -0.02 & 0.00 & 0.03 & 0.01 & 0.00 & 0.00 & 0.02 & 0.02 & -0.02 & 0.03 & 0.01 & 0.03 & 0.15 & 0.32 & 1.00 & & & \\
\hline 19 & Portfolio rebalancing needs & 0.17 & 0.01 & 0.02 & -0.02 & -0.07 & -0.07 & 0.07 & -0.07 & -0.06 & -0.06 & -0.07 & -0.07 & -0.02 & -0.01 & -0.02 & 0.20 & 0.17 & 0.12 & 0.08 & 1.00 & & \\
\hline 20 & Liquidity needs & 0.10 & 0.00 & 0.03 & -0.07 & -0.07 & -0.10 & 0.08 & -0.04 & -0.03 & 0.05 & -0.01 & -0.07 & -0.02 & -0.03 & -0.02 & 0.09 & 0.22 & 0.21 & 0.10 & 0.29 & 1.00 & \\
\hline 21 & Risk aversion & 0.34 & 0.02 & -0.01 & 0.01 & 0.01 & 0.00 & 0.06 & 0.02 & 0.02 & 0.00 & -0.01 & -0.03 & -0.01 & -0.03 & -0.02 & -0.01 & -0.02 & 0.00 & -0.03 & -0.05 & -0.01 & 1.00 \\
\hline
\end{tabular}

Table 8 Summary Statistics and Pairwise Correlation Coefficients of Dummy Variables Based on Survey Responses

Note: This table shows the mean value of dummy variables based on survey responses and their pair-wise correlation coefficients. See Table A2 in the Online Appendix for more details about variable definitions. The bold fonts highlight correlation coefficients for survey responses that capture different aspects of the same mechanism. 
Panel A: Volume-Weighted Past One-Month Count of Up-Limit Hits Based on Initial Buys

\begin{tabular}{|c|c|c|c|c|c|c|c|c|c|c|c|c|}
\hline \multirow[b]{3}{*}{ Gambling preference, blockbusters } & \multicolumn{12}{|c|}{ Panel A: Volume-Weighted Past One-Month Count of Up-Limit Hits Based on Initial Buys } \\
\hline & & $\begin{array}{r}\text { Full sa } \\
\text { (2018:01 - }\end{array}$ & $\begin{array}{l}\text { mple } \\
\text { 2019:06 }\end{array}$ & & & $\begin{array}{r}\text { Pre-su } \\
(2018: 01-\end{array}$ & $\begin{array}{l}\text { vey } \\
\text { 2018:09) }\end{array}$ & & & $\begin{array}{r}\text { Post-s } \\
(2018: 10-\end{array}$ & $\begin{array}{l}\text { Irvey } \\
\text { 2019:06) }\end{array}$ & \\
\hline & $\begin{array}{c}0.112 * * * \\
(3.875)\end{array}$ & $\begin{array}{c}0.109^{* * *} \\
(3.768)\end{array}$ & & & $\begin{array}{c}0.087^{* * * *} \\
(3.640)\end{array}$ & $\begin{array}{c}0.086^{* * * *} \\
(3.608)\end{array}$ & & & $\begin{array}{c}0.142 * * * \\
(3.660)\end{array}$ & $\begin{array}{c}0.139^{* * *} \\
(3.573)\end{array}$ & & \\
\hline Gambling preference, lotteries & & & $\begin{array}{c}0.038 \\
(1.257)\end{array}$ & $\begin{array}{c}0.019 \\
(0.653)\end{array}$ & & & $\begin{array}{c}0.025 \\
(1.013)\end{array}$ & $\begin{array}{c}0.018 \\
(0.727)\end{array}$ & & & $\begin{array}{c}0.051 \\
(1.237)\end{array}$ & $\begin{array}{c}0.029 \\
(0.698)\end{array}$ \\
\hline Male & & $\begin{array}{c}-0.034 \\
(-1.164)\end{array}$ & & $\begin{array}{c}-0.033 \\
(-1.140)\end{array}$ & & $\begin{array}{c}-0.011 \\
(-0.444)\end{array}$ & & $\begin{array}{c}-0.01 \\
(-0.403)\end{array}$ & & $\begin{array}{c}-0.035 \\
(-0.884)\end{array}$ & & $\begin{array}{c}-0.034 \\
(-0.866)\end{array}$ \\
\hline Controls & NO & YES & NO & YES & NO & YES & NO & YES & NO & YES & NO & YES \\
\hline$R 2$ & 0.004 & 0.023 & 0.000 & 0.019 & 0.004 & 0.017 & 0.000 & 0.014 & 0.004 & 0.020 & 0.000 & 0.016 \\
\hline $\mathrm{N}$ & 4,145 & 4,145 & 4,145 & 4,145 & 3,435 & 3,435 & 3,435 & 3,435 & 3,550 & 3,550 & 3,550 & 3,550 \\
\hline
\end{tabular}

Panel B: Volume-Weighted Past One-Quarter Count of Up-Limit Hits Based on Initial Buys

\begin{tabular}{|c|c|c|c|c|c|c|c|c|c|c|c|c|}
\hline \multirow[b]{2}{*}{ Gambling preference, blockbusters } & \multicolumn{4}{|c|}{$\begin{array}{c}\text { Full sample } \\
(2018: 01-2019: 06)\end{array}$} & \multicolumn{4}{|c|}{$\begin{array}{c}\text { Pre-survey } \\
(2018: 01-2018: 09)\end{array}$} & \multicolumn{4}{|c|}{$\begin{array}{c}\text { Post-survey } \\
(2018: 10-2019: 06)\end{array}$} \\
\hline & $\begin{array}{l}0.209^{* * *} \\
(4.550)\end{array}$ & $\begin{array}{l}0.199 * * * \\
(4.299)\end{array}$ & & & $\begin{array}{l}0.174 * * * \\
(4.354)\end{array}$ & $\begin{array}{c}0.169^{* * *} \\
(4.240)\end{array}$ & & & $\begin{array}{c}0.256^{* * *} \\
(4.066)\end{array}$ & $\begin{array}{c}0.239^{* * *} \\
(3.774)\end{array}$ & & \\
\hline Gambling preference, lotteries & & & $\begin{array}{l}0.091^{*} \\
(1.897)\end{array}$ & $\begin{array}{c}0.055 \\
(1.144)\end{array}$ & & & $\begin{array}{l}0.103 * * \\
(2.389)\end{array}$ & $\begin{array}{c}0.086 * * \\
(1.994)\end{array}$ & & & $\begin{array}{c}0.071 \\
(1.107)\end{array}$ & $\begin{array}{c}0.024 \\
(0.373)\end{array}$ \\
\hline Male & & $\begin{array}{l}-0.051 \\
(-1.084)\end{array}$ & & $\begin{array}{c}-0.049 \\
(-1.051)\end{array}$ & & $\begin{array}{c}-0.04 \\
(-0.996)\end{array}$ & & $\begin{array}{c}-0.039 \\
(-0.949)\end{array}$ & & $\begin{array}{c}-0.051 \\
(-0.798)\end{array}$ & & $\begin{array}{c}-0.05 \\
(-0.784)\end{array}$ \\
\hline Controls & NO & YES & NO & YES & NO & YES & NO & YES & NO & YES & NO & YES \\
\hline$R 2$ & 0.005 & 0.025 & 0.001 & 0.021 & 0.006 & 0.017 & 0.002 & 0.013 & 0.005 & 0.021 & 0.000 & 0.017 \\
\hline $\mathrm{N}$ & 4,145 & 4,145 & 4,145 & 4,145 & 3,435 & 3,435 & 3,435 & 3,435 & 3,550 & 3,550 & 3,550 & 3,550 \\
\hline
\end{tabular}

Table 9 Validating Gambling Preferences Using Gambling Behavior

Note: This table studies the relationship between survey-based gambling preference and transaction-based gambling behavior. Gambling behavior is measured by the buy-volume (in RMB) weighted average of the past one-month (Panel A) or one-quarter (Panel B) number of up-limit hits based on the stocks an investor purchases in a given sample period. A purchase is considered as an initial buy if the investor holds zero share of the stock before the purchase. Each panel presents OLS regression results based on three sample periods: full (January 2018 through June 2019), pre-survey (January 2018 through September 2018), and post-survey (October 2018 through June 2019). Gambling preference (blockbusters) equals one if an investor answers "Strongly agree" or "Agree" when asked if they aim to make a lot of money quickly through stock investment and zero otherwise. Gambling preference (lotteries) equals one if an investor answers "Strongly agree" or "Agree" when asked if they often think of stocks as lotteries and zero otherwise. See Table 5 for the exact phrasing of the survey questions. Control variables include age, gender, net worth, income, trading experience, account size, and education. $T$-statistics are based on robust standard errors and are reported in parentheses. 


\begin{tabular}{|c|c|c|c|c|c|c|c|c|}
\hline & (1) & (2) & (3) & (4) & $(5)$ & (6) & (7) & (8) \\
\hline Actual performance in 2017 & $\begin{array}{c}4.104 * * * \\
(5.332)\end{array}$ & & & & & & & \\
\hline Overplacement, performance & $\begin{array}{c}15.695 * * * \\
(2.760)\end{array}$ & & & & & & & \\
\hline Financial literacy, dummy & & $\begin{array}{c}11.922 * * * \\
(3.127)\end{array}$ & & & & & & \\
\hline Overplacement, literacy & & $\begin{array}{c}1.729 \\
(0.400)\end{array}$ & & & & & & \\
\hline Miscalibration & & & $\begin{array}{c}1.116 \\
(0.289)\end{array}$ & & & & & \\
\hline Underestimation of trading costs & & & & $\begin{array}{c}-3.549 \\
(-0.980)\end{array}$ & & & & \\
\hline Do not consider trading costs & & & & & $\begin{array}{c}-2.143 \\
(-0.548)\end{array}$ & & & \\
\hline Do not think bid-ask spread is a cost & & & & & & $\begin{array}{c}-15.135^{* * *} \\
(-4.254)\end{array}$ & & \\
\hline Extrapolation, up & & & & & & & $\begin{array}{c}4.379 \\
(1.110)\end{array}$ & \\
\hline Extrapolation, down & & & & & & & & $\begin{array}{c}3.810 \\
(1.005)\end{array}$ \\
\hline $\mathrm{R} 2$ & 0.007 & 0.002 & 0.000 & 0.000 & 0.000 & 0.004 & 0.000 & 0.000 \\
\hline & (9) & $(10)$ & $(11)$ & (12) & (13) & (14) & $(15)$ & $(16)$ \\
\hline Gambling preference, blockbusters & $\begin{array}{c}10.924 * * * \\
(2.878)\end{array}$ & & & & & & & \\
\hline Gambling preference, lotteries & & $\begin{array}{c}2.750 \\
(0.684)\end{array}$ & & & & & & \\
\hline Realization utility, winners & & & $\begin{array}{c}7.188 * \\
(1.874)\end{array}$ & & & & & \\
\hline Realization utility, losers & & & & $\begin{array}{c}0.409 \\
(0.093)\end{array}$ & & & & \\
\hline Sensation seeking, novelty & & & & & $\begin{array}{c}10.184 * * \\
(2.270)\end{array}$ & & & \\
\hline Sensation seeking, volatility & & & & & & $\begin{array}{c}11.984 * * * \\
(2.885)\end{array}$ & & \\
\hline Perceived information advantage & & & & & & & $\begin{array}{c}21.747 * * * \\
(4.254)\end{array}$ & \\
\hline Dismissive of others' information & & & & & & & & $\begin{array}{c}4.778 \\
(1.318)\end{array}$ \\
\hline $\mathrm{R} 2$ & 0.002 & 0.000 & 0.001 & 0.000 & 0.001 & 0.002 & 0.005 & 0.000 \\
\hline & $(17)$ & $(18)$ & (19) & $(20)$ & & & & \\
\hline Social influence & $\begin{array}{c}-15.647 * * * \\
(-3.317)\end{array}$ & & & & & & & \\
\hline Advisor influence & & $\begin{array}{c}-16.469^{* *} \\
(-2.708)\end{array}$ & & & & & & \\
\hline Portfolio rebalancing needs & & & $\begin{array}{c}12.652 * * \\
(2.423)\end{array}$ & & & & & \\
\hline Liquidity needs & & & & $\begin{array}{l}-9.974 * \\
(-1.853)\end{array}$ & & & & \\
\hline $\mathrm{R} 2$ & 0.002 & 0.001 & 0.001 & 0.001 & & & & \\
\hline
\end{tabular}

Note: In this table, we run univariate cross-sectional regressions of each investor's turnover (\%) on survey-based trading motives. $T$-statistics are based on robust standard errors and are reported in parentheses. See Table A2 in the Online Appendix for more details about variable definitions. 


\begin{tabular}{|c|c|c|c|}
\hline \multicolumn{4}{|c|}{$\begin{array}{l}\text { Dependent Variable: Average Monthly Turnover Ratio (\%) } \\
\text { (October 2018 - June 2019) }\end{array}$} \\
\hline Actual performance in 2017 & $\begin{array}{c}4.198^{* * *} \\
(5.219)\end{array}$ & Gambling preference, blockbusters & $\begin{array}{c}11.764 * * * \\
(2.920)\end{array}$ \\
\hline Overplacement, performance & $\begin{array}{c}11.549 * * \\
(2.063)\end{array}$ & Gambling preference, lotteries & $\begin{array}{c}-1.159 \\
(-0.263)\end{array}$ \\
\hline Financial literacy, dummy & $\begin{array}{l}7.065^{*} \\
(1.800)\end{array}$ & Sensation seeking, novelty & $\begin{array}{c}6.598 \\
(1.360)\end{array}$ \\
\hline Overplacement, literacy & $\begin{array}{c}-2.621 \\
(-0.625)\end{array}$ & Sensation seeking, volatility & $\begin{array}{c}3.632 \\
(0.824)\end{array}$ \\
\hline Miscalibration of uncertainty & $\begin{array}{c}-2.989 \\
(-0.764)\end{array}$ & Perceived information advantage & $\begin{array}{c}15.660 * * * \\
(2.988)\end{array}$ \\
\hline Do not consider trading costs & $\begin{array}{c}-3.989 \\
(-1.071)\end{array}$ & Dismissive of others' information & $\begin{array}{c}2.942 \\
(0.805)\end{array}$ \\
\hline Underestimation of trading costs & $\begin{array}{l}-4.029 \\
(-1.052)\end{array}$ & Social influence & $\begin{array}{c}-7.839 \\
(-1.616)\end{array}$ \\
\hline Do not think bid-ask spread is a cost & $\begin{array}{c}-9.456 * * * \\
(-2.650)\end{array}$ & Advisor influence & $\begin{array}{l}-12.089^{*} \\
(-1.943)\end{array}$ \\
\hline Extrapolation, up & $\begin{array}{c}-1.255 \\
(-0.254)\end{array}$ & Portfolio rebalancing needs & $\begin{array}{c}12.571 * * \\
(2.280)\end{array}$ \\
\hline Extrapolation, down & $\begin{array}{c}-1.208 \\
(-0.262)\end{array}$ & Liquidity needs & $\begin{array}{c}-7.651 \\
(-1.335)\end{array}$ \\
\hline Realization utility, winners & $\begin{array}{l}7.049^{*} \\
(1.848)\end{array}$ & Risk Aversion & $\begin{array}{c}-2.943 \\
(-0.692)\end{array}$ \\
\hline Realization utility, losers & $\begin{array}{c}-2.321 \\
(-0.538)\end{array}$ & Expected 1-year market return & $\begin{array}{l}0.709^{*} \\
(1.901)\end{array}$ \\
\hline Gender: male & $\begin{array}{c}21.488 * * * \\
(6.124)\end{array}$ & $\begin{array}{l}\text { Controls } \\
\mathrm{N} \\
R 2\end{array}$ & $\begin{array}{c}\text { YES } \\
4,648 \\
0.089\end{array}$ \\
\hline
\end{tabular}

$t$-statistics in parentheses; $* * * \mathrm{p}<0.01,{ }^{* *} \mathrm{p}<0.05,{ }^{*} \mathrm{p}<0.1$

Table 11: Regression Results Using the Full Set of Trading Motives

Note: In this table, we run a multivariate cross-sectional regression of each investor's turnover on all surveybased measures of trading motives. Control variables include age, gender, wealth, income, trading experience, account size, and education. $T$-statistics are based on robust standard errors and are reported in parentheses. See Table A2 in the Online Appendix for more details about variable definitions. 


\section{Panel A: Sort investors by their answers to the statement about gambling preference, blockbusters}

\begin{tabular}{|c|c|c|c|c|c|c|c|c|}
\hline & \multicolumn{6}{|c|}{ Monthly Turnover } & \multicolumn{2}{|c|}{ Monthly Raw Returns } \\
\hline & $\mathrm{P} 10$ & $\mathrm{P} 25$ & $\mathrm{P} 75$ & P90 & Median & Mean & Median & Mean \\
\hline 1. Strongly disagree & $0 \%$ & $4 \%$ & $99 \%$ & $206 \%$ & $25 \%$ & $74 \%$ & $0.19 \%$ & $0.15 \%$ \\
\hline 2. Disagree & $0 \%$ & $3 \%$ & $100 \%$ & $222 \%$ & $31 \%$ & $77 \%$ & $0.00 \%$ & $0.04 \%$ \\
\hline 3. Neutral & $0 \%$ & $5 \%$ & $112 \%$ & $238 \%$ & $33 \%$ & $84 \%$ & $0.01 \%$ & $0.11 \%$ \\
\hline 4. Agree & $0 \%$ & $7 \%$ & $117 \%$ & $248 \%$ & $42 \%$ & $90 \%$ & $0.03 \%$ & $-0.04 \%$ \\
\hline 5. Strongly agree & $0 \%$ & $5 \%$ & $119 \%$ & $274 \%$ & $42 \%$ & $95 \%$ & $0.00 \%$ & $-0.20 \%$ \\
\hline $5-1$ & $0 \%$ & $\mathbf{0 \%}$ & $20 \%$ & $68 \%$ & $17 \%$ & $21 \% * *$ & $-0.19 \%$ & $-0.35 \%$ \\
\hline Annual transaction fee $(5-1)$ & $0.00 \%$ & $0.00 \%$ & $0.60 \%$ & $1.96 \%$ & $0.51 \%$ & $0.63 \%$ & & \\
\hline
\end{tabular}

Panel B: Sort investors by their perceived information advantages

\begin{tabular}{|c|c|c|c|c|c|c|c|c|}
\hline & \multicolumn{6}{|c|}{ Monthly Turnover } & \multicolumn{2}{|c|}{ Monthly Raw Returns } \\
\hline & P10 & $\mathrm{P} 25$ & $\mathrm{P} 75$ & P90 & Median & Mean & Median & Mean \\
\hline 1. Never & $0 \%$ & $4 \%$ & $102 \%$ & $232 \%$ & $30 \%$ & $76 \%$ & $0.10 \%$ & $0.12 \%$ \\
\hline 2. Rarely & $0 \%$ & $3 \%$ & $100 \%$ & $218 \%$ & $32 \%$ & $76 \%$ & $0.07 \%$ & $0.06 \%$ \\
\hline 3. Sometimes & $0 \%$ & $5 \%$ & $109 \%$ & $244 \%$ & $34 \%$ & $86 \%$ & $0.00 \%$ & $0.08 \%$ \\
\hline 4. Often & $0 \%$ & $11 \%$ & $139 \%$ & $286 \%$ & $46 \%$ & $103 \%$ & $0.00 \%$ & $-0.13 \%$ \\
\hline 5. Always & $0 \%$ & $10 \%$ & $139 \%$ & $253 \%$ & $44 \%$ & $100 \%$ & $0.00 \%$ & $-0.01 \%$ \\
\hline $5-1$ & $0 \%$ & $6 \%$ & $37 \%$ & $21 \%$ & $14 \% * *$ & $24 \% * *$ & $-0.10 \%$ & $-0.13 \%$ \\
\hline Annual transaction fee $(5-1)$ & $0.00 \%$ & $0.18 \%$ & $1.11 \%$ & $0.63 \%$ & $0.42 \%$ & $0.72 \%$ & & \\
\hline
\end{tabular}

Table 12 Additional Analysis of Gambling Preference, Blockbusters and Perceived Information Advantage

Note: In Panel A, we sort investors into five groups based on their answers to the question, "Do you agree with the following statement? When I trade stocks, I often wish to select those stocks whose price would rise sharply in a short period time so that I can make a lot of money quickly." In Panel B, we sort investors into five groups based on their answers to the question, "When you decide to trade a stock, how often do you believe that you know the stock better than others?" In each panel, we tabulate the summary statistics of monthly turnover ratios (monthly raw returns) for investors in each group. The last one or two rows report the differences between the bottom and top groups. When testing for the significance of the differences, we use robust standard errors. 


\begin{tabular}{|c|c|c|c|c|c|c|c|c|c|}
\hline & \multicolumn{2}{|c|}{$\begin{array}{c}\text { Panel A: } \\
\text { Monthly Turnover }\end{array}$} & \multicolumn{7}{|c|}{$\begin{array}{c}\text { Panel B: } \\
\text { Characteristics of Stocks Bought }\end{array}$} \\
\hline & Mean & Median & $\begin{array}{c}\text { Past 30-day \# } \\
\text { of Up-limit } \\
\text { Hits }\end{array}$ & $\begin{array}{c}\text { Past 30-day } \\
\text { Return } \\
\text { Volatility } \\
(\%)\end{array}$ & $\begin{array}{c}\text { Past 30-day } \\
\text { Return } \\
(\%)\end{array}$ & $\begin{array}{c}\text { Size } \\
\text { (Billion } \\
\text { RMB) }\end{array}$ & Beta & $\mathrm{B} / \mathrm{M}$ & $\begin{array}{c}\text { Future } \\
\text { 30-day } \\
\text { Return (\%) }\end{array}$ \\
\hline 1 (lowest) & 60.37 & 29.43 & 0.70 & 3.30 & 10.65 & 36.46 & 0.94 & 0.66 & -0.91 \\
\hline 2 & 80.76 & 38.69 & 0.67 & 3.36 & 10.28 & 35.14 & 0.95 & 0.62 & -0.91 \\
\hline 3 & 71.91 & 29.49 & 0.80 & 3.41 & 11.18 & 29.79 & 0.99 & 0.61 & -0.81 \\
\hline 4 & 92.69 & 43.92 & 0.74 & 3.48 & 10.13 & 23.37 & 1.04 & 0.58 & -0.88 \\
\hline 5 (highest) & 157.29 & 98.45 & 1.12 & 3.78 & 14.63 & 20.13 & 1.02 & 0.59 & -2.02 \\
\hline $5-1$ & $96.92 * * *$ & $69.02 * * *$ & $0.42 * * *$ & $0.48 * * *$ & $3.97 * * *$ & $-16.34 * * *$ & $0.09 * * *$ & $-0.07 * * *$ & $-1.11 * *$ \\
\hline
\end{tabular}

$t$-statistics in parentheses; *** $\mathrm{p}<0.01, * * \mathrm{p}<0.05, * \mathrm{p}<0.1$

Table 13: Trading Characteristics for Investors Sorted on Transaction-Based Gambling Behavior

Note: We construct a measure for transaction-based gambling behavior for each investor in two steps. First, for each of the nine months prior to the survey (January 2018 through September 2018), we first calculate the past one-month count of up-limit hits of the stock for each buy transaction and then take the transaction value-weighted average across all buy orders. Then, we take the time-series average value weighted by monthly buy values. We then sort investors into five groups according to transaction-based gambling behavior and compare their behaviors after the survey, from October 2018 through June 2019. In Panel A (B), we tabulate the summary statistics of monthly turnover ratios (characteristics of stocks bought) for investors in each group. In the last row of each panel, we report the differences between the bottom and top groups. When testing for the significance of the differences, standard errors are adjusted for heteroscedasticity. 


\begin{tabular}{lclc}
\hline \hline \multicolumn{1}{c}{$\begin{array}{c}\text { Dependent Variable: Volume-Weighted Past One-Month Count of Up-Limit Hits Based on Initial Buys } \\
\text { (January 2018 }\end{array}$} & September 2018) \\
\hline Actual performance in 2017 & $-0.009^{* *}$ & Gambling preference, blockbusters & $0.071^{* * *}$ \\
& $(-2.533)$ & & $(3.598)$ \\
Overplacement, performance & 0.002 & Gambling preference, lotteries & -0.011 \\
& $(0.071)$ & & $(-0.482)$ \\
Financial literacy, dummy & -0.031 & Sensation seeking, novelty & -0.032 \\
& $(-1.478)$ & & $(-1.518)$ \\
Overplacement, literacy & -0.014 & Sensation seeking, volatility & 0.022 \\
& $(-0.633)$ & & $(1.030)$ \\
Miscalibration of uncertainty & 0.017 & Perceived information advantage & $0.049^{* *}$ \\
& $(0.942)$ & & $(2.097)$ \\
Do not consider trading costs & $0.040^{* *}$ & Dismissive of others' information & -0.001 \\
& $(2.221)$ & & $(-0.031)$ \\
Underestimation of trading costs & -0.005 & Social influence & -0.005 \\
& $(-0.276)$ & & $(-0.178)$ \\
Do not think bid-ask spread is a cost & $-0.043^{* *}$ & Advisor influence & 0.025 \\
& $(-2.436)$ & & $(0.647)$ \\
Extrapolation, up & 0.003 & Portfolio rebalancing needs & $-0.039^{*}$ \\
& $(0.133)$ & & $(-1.741)$ \\
Extrapolation, down & -0.001 & Liquidity needs & 0.021 \\
Realization utility, winners & $(-0.045)$ & & $(0.679)$ \\
Realization utility, losers & 0.015 & Risk Aversion & 0.004 \\
Gender: male & $(0.843)$ & & $(0.205)$ \\
& 0.009 & Expected 1-year market return & 0.000 \\
& $(0.409)$ & & $(0.266)$ \\
& 0.011 & Controls & YES \\
& $(0.623)$ & N & 3,528 \\
& & $R 2$ & 0.031 \\
\hline \hline
\end{tabular}

$t$-statistics in parentheses; ${ }^{* * *} \mathrm{p}<0.01,{ }^{* *} \mathrm{p}<0.05,{ }^{*} \mathrm{p}<0.1$

Table 14: Regressing Transaction-Based Gambling Behavior on Survey-Based Trading Motives

Note: In this table, we run a multivariate cross-sectional regression of each investor's transaction-based gambling behavior on survey-based trading motives. We construct a measure for transaction-based gambling behavior for each investor in two steps. First, for each of the nine months prior to the survey (January 2018 through September 2018), we first calculate the past one-month count of up-limit hits of the stock for each buy transaction and then take the transaction value weighted average across all buy orders. Second, we take the time-series average value weighted by monthly buy values. Control variables include age, gender, wealth, income, trading experience, account size, and education. $T$-statistics are based on robust standard errors and are reported in parentheses. See Table A2 in the Online Appendix for more details about variable definitions. 